\title{
IV. LES LANGUES DE LA DIPLOMATIE ET LA TRADUCTION DE DOCUMENTS JURIDIQUES JUSQU'EN 1648
}

\section{Bilan historiographique et aperçu de l'histoire des langues de la diplomatie et de la traduction jusqu'aux Temps modernes}

Les historiens n'ont pas encore vraiment découvert la traduction en tant que source qui peut nous renseigner sur les réalités et l'imaginaire du temps passé. L'histoire diplomatique du XIX ${ }^{\mathrm{e}}$ siècle, aujourd'hui dite »classique«, s'est en grande partie consacrée au récit chronologique des événements qui ont marqué l'histoire des relations entre les différents États de l'Europe. Elle a profité de l'ouverture au public d'un grand nombre d'archives jusqu'alors fermées, et nous a laissé, outre des éditions de sources d'une très grande valeur, plusieurs chefsd'œuvre historiographiques, proches des réalités du temps passé, et dont la lecture peut, par conséquent, toujours profiter à l'historien moderne. Au XXe siècle, l'histoire diplomatique a été négligée, pendant un certain temps, au profit de l'histoire sociale et économique et de celle des mentalités. Pourtant, en 1991, André Corvisier a pu constater, apparemment avec une certaine satisfaction, "un retour en grâce du politique et de l'événementiel« ainsi qu'un »réveil de l'histoire militaire et de l'histoire des relations internationales «'. Si, comme Lucien Bély l'a souligné en 1998, les »relations internationales se nourrissent de l'événement et donnent une place à l'action individuelle «, il est certain que leur histoire a beaucoup profité d'un regard inspiré par une vision plus vaste de l'histoire des sociétés, englobant les institutions, l'économie et les mentalités ${ }^{2}$. Les recherches récentes en histoire des relations internationales essaient de répondre à des interrogations nouvelles, qui abordent cet objet d'une manière plus structurelle sans pour autant négliger les réalités concrètes, éléments fondamentaux de toute connaissance.

Parmi ces interrogations nouvelles de l'historiographie moderne, on peut citer les conditions du travail quotidien des diplomates ${ }^{3}$. Si l'on veut porter son regard sur les diplomates au travail, l'instrument même de toutes leurs négociations et des lettres et mémoires qu'ils ont rédigés, c'est-à-dire leur langue, ne se situe cer-

1 André CoRvisier, Introduction, dans: Lucien BELY, Jean BÉRENGER, André CoRvisier, Guerre et paix dans l'Europe du XVIIe siècle, t. I, Paris ${ }^{2} 1991$ (Regards sur l'histoire. Histoire moderne, 77), p. 7-9, ici p. 7.

2 Cf. Lucien BÉly, L'invention de la diplomatie, dans: ID. (dir.), L'invention de la diplomatie. Moyen Âge - Temps modernes, avec le concours d'Isabelle RICHEFORT, Paris 1998, p. 11-23, ici p. 11-12.

${ }^{3}$ Cf., par exemple, Babel (dir.), Le diplomate au travail; Michael RoHRSCHNEIDER, Arno STROHMEYER (dir.), Wahrnehmung des Fremden. Differenzerfahrungen von Diplomaten im 16. und 17. Jahrhundert, Münster 2007 (Schriftenreihe der Vereinigung zur Erforschung der Neueren Geschichte e.V., 31). 
tainement pas parmi les problèmes mineurs. Selon Lucien Bély, l'étude »des langues utilisées [par les diplomates] pendant les discussions est un pas décisif pour une approche culturelle, au sens le plus large, de la pratique politique ${ }^{4}$. Pourtant, ce sujet n'a jamais été traité d'une manière exhaustive ni cohérente. Certains traités de diplomatie et de droit international des $\mathrm{XIX}^{\mathrm{e}}$ et $\mathrm{XX}^{\mathrm{e}}$ siècles offrent des aperçus historiques d'environ deux à cinq pages consacrés à l'histoire des langues diplomatiques. Des ouvrages historiques sur les congrès de diplomates aux XVIIe et XVIII siècles examinent aussi la question. Ces ouvrages rédigés par des historiens sont particulièrement intéressants pour notre question parce qu'ils ne se nourrissent pas uniquement d'un certain stock d'exemples historiques toujours cités dans les manuels de diplomates et les travaux des juristes ainsi que par les linguistes ${ }^{5}$. Les historiens peuvent en effet se fonder sur une excellente maîtrise des sources, qui est indispensable pour avancer nos connaissances.

Les études entreprises par les philologues méritent pour autant toujours notre attention toute particulière. Le très beau livre publié, en 1998, par Françoise Waquet sur »Le latin ou l'empire d'un signe « ${ }^{6}$ offre une synthèse de la plupart des ouvrages antérieurs bien qu'il ne se veuille pas, comme l'auteur le souligne d'emblée, une étude »d'ordre encyclopédique «7 ${ }^{7}$. Les six pages où elle parle de la place du latin dans l'administration des États et dans la diplomatie se situent parmi les meilleures qui aient jamais été écrites sur ce sujet ${ }^{8}$. Cependant, pour l'historien spécialiste des Temps modernes, de nombreuses questions subsistent. Il n'en reste pas moins que le livre de Françoise Waquet garde un caractère indispensable pour toute étude plus approfondie dans le domaine limité qu'est la diplomatie, car il permet d'interpréter ses résultats sur le fond d'une histoire générale de la culture latine de l'Occident.

Dans le cadre de notre problématique, un regard sur les langues des relations franco-allemandes et sur la culture européenne qui les entourait s'avère indispensable, puisque la vision française du Saint Empire romain germanique ne peut se comprendre sans faire une place au filtre par lequel la perception française devait nécessairement passer: la traduction. Notre modeste contribution à l'éclaircissement de cette vaste question des langues, vaste même si on la considère seulement dans les relations entre les États et entre les peuples de l'Occident moderne, consistera donc à analyser les usages linguistiques observés au premier congrès diplomatique de l'histoire moderne, le congrès de Westphalie (1643-1649) - parce

${ }^{4}$ Lucien BÉLY, L'Art de la paix en Europe. Naissance de la diplomatie moderne, XVIeXVIII ${ }^{\mathrm{e}}$ siècle, Paris 2007, p. 244, n. 1.

5 Ils se fondent en général sur des documents imprimés qui, contrairement aux documents d'archives indispensables pour approfondir véritablement nos connaissances sans toujours répéter les mêmes clichés, sont les seules sources qui soient à leur portée.

6 Françoise WAQUET, Le latin ou l'empire d'un signe, XVIe-XXe siècle, Paris 1998.

7 Ibid., p. 11.

${ }^{8}$ Cf. ibid., p. 119-123, avec les notes p. 345-346; signalons toutefois que ce ne fut pas le comte d'Avaux mais le duc de Longueville qui dirigea l'ambassade française au congrès de Westphalie, et que la Hongrie royale n'était pas unie à l'Empire, mais seulement gouvernée par un Habsbourg. 
que celui-ci devint le modèle des congrès de diplomates ultérieurs et qu'il consacra dans une très large mesure le cérémonial diplomatique moderne - et à retracer l'histoire des langues et de la traduction diplomatiques dans les relations francoallemandes au siècle suivant, jusqu'en 1756. Durant toute cette période, la diplomatie s'est révélée un monde polyglotte. Par conséquent, elle devait faire face à un problème particulier qui découlait de ce caractère polyglotte de l'époque, c'est-à-dire la traduction. Comme dans ce monde polyglotte des diplomates, le latin et le français étaient les deux langues prépondérantes, la traduction du latin en français revêtait une importance particulière. Toujours est-il que que le problème de la traduction n'est pas confiné aux Temps modernes.

Les recherches sur l'histoire de l'emploi des langues et sur celle de la traduction dans la diplomatie moderne, en réalité inséparables, accusent (malgré certaines études spécialisées, notamment sur les drogmans ${ }^{9}$ ) un retard certain par rapport aux autres époques, bien qu'il faille constater que, d'une manière générale, l'histoire des langues et de la traduction diplomatiques n'est pas encore écrite. Or, celui qui cherche à comprendre les origines du rôle politique des langues et de la traduction dans le monde moderne doit remonter au Moyen Âge, sinon à l'Antiquité pour retrouver leurs racines idéologiques, de sorte que l'absence d'ouvrages de référence paraît particulièrement grave. Charlemagne, par exemple, chercha déjà à assurer l'unité culturelle de son empire en faisant traduire des textes en langue vernaculaire ${ }^{10}$. L'objectif de la traduction au Moyen Âge pouvait être soit de consolider l'unité d'un empire en créant un espace judiciaire et culturel unique ${ }^{11}$, soit de mettre en relief le caractère universel du pouvoir. Les conclusions des médiévistes peuvent être très utiles pour guider la réflexion sur les langues et sur la traduction aux Temps modernes, bien que les problèmes qui se posent aux XVIIe et XVIII ${ }^{e}$ siècles soient en partie assez différents de ceux du Moyen Âge. La diplomatie moderne connaît à la fois la traduction de textes latins en langue vernaculaire - prédominant dans l'Occident chrétien médiéval et attestée au XVIIe siècle surtout pour les traités et les documents à caractère officiel échangés au

${ }^{9}$ Cf. Géraud PoumarèdE, article »Drogmans et jeunes de langue «, dans: Bély (dir.), Dictionnaire de l'Ancien Régime, p. 436; signalons encore, parmi les publications plus récentes: Frédéric HitZel, Les Jeunes de langue de Péra-lès-Constantinople, dans: XVIIIe siècle 28 (1996), p. 57-70; Antoine GAUTIER, Les drogmans des consulats, dans: Jörg ULBERT, Gérard LE BOUËDEC (dir.), La fonction consulaire à l'époque moderne. L'affirmation d'une institution économique et politique (1500-1800), Rennes 2006, p. 85-103.

$10 \mathrm{M}$ [arc] A[eilko] ARIS, article »Übersetzung, allgemeine Voraussetzungen und theoretische Grundlagen«, dans: Lexikon des Mittelalters, 9 vol. et index, Munich et al. 1980-1999 (en partie 21999), t. VIII (1997), col. 1163-1166, ici col. 1163; cf. aussi l'article collectif: "Übersetzer, Übersetzungen «, dans: Lexikon des Mittelalters, t. VIII, col. 1148-1163.

11 Frédéric II, très sensible aux problèmes de traduction, et les rois normands de Sicile, ses prédécesseurs, avaient déjà tenté de créer l'unité de leur peuple à travers l'uniformisation linguistique; sur les usages linguistiques et la traduction à la cour de Frédéric II et des rois normands, cf. Ernst H. KANTOROwICZ, Kaiser Friedrich der Zweite, 2 vol., Düsseldorf, Munich 1963 [réimpression de l'édition de Berlin 1927-1931], en particulier p. 237-238, 251253 (tentatives des Normands pour unifier le peuple en créant l'unité linguistique), 262-267, 271, 273, 281-282 (sensibilité de Frédéric II aux problèmes de traduction) et 414. 
cours des négociations et pour la correspondance entre les cours souveraines mais aussi la traduction d'une langue moderne en une autre, lors des congrès et réunions de plénipotentiaires, etc. Au XVII ${ }^{\mathrm{e}}$ siècle, la traduction devient un problème important puisque se développent les relations internationales «, se multiplient les résidents et les ambassadeurs ordinaires en Europe ainsi que les actes diplomatiques, ce que le Moyen Âge n'avait pas connu avec une telle ampleur; dans cette optique, les congrès de paix, surtout celui de Westphalie, mais aussi ceux de Nimègue, de Ryswick et d'Utrecht, apparaissent comme des objets de recherches très fructueux.

Si les ouvrages sur les usages linguistiques de la diplomatie moderne manquent quasi complètement, certains travaux (historiques, philosophiques, linguistiques ou littéraires) abordent des problèmes fondamentaux des langues et de la traduction diplomatiques. Sans prétendre donner un tableau exhaustif de ces contributions ${ }^{12}$, citons par exemple la $» P e t i t e$ histoire de la traduction en Occident«, d'Henri Van Hoof ${ }^{13}$; la $»$ Théorie et l'histoire de la traduction «, de Georges Mounin ${ }^{14}$; »Après Babel«, de George Steiner ${ }^{15}$; l'»Histoire de la traduction «, de L. G. Kelly ${ }^{16}$; et l'ouvrage d'Edmond Cary sur la traduction dans le monde »moderne« (c'est-à-dire contemporain), qui comprend un chapitre sur la traduction diplomatique et administrative ${ }^{17}$. Pour la traduction à l'aube des Temps modernes, il est toujours utile de se reporter à »La théorie de la traduction au début de la Renaissance «, par Paul Herbert Larwill ${ }^{18}$, et, pour les interprètes dans l'Antiquité et au Moyen Âge, aux contributions d'Alfred Hermann et d'Edgar Glässer ${ }^{19}$, qui font état du rôle politique éminent de ceux-ci, car ils avaient accès aux négociations les plus secrètes de leurs chefs politiques ou militaires - un rôle qui leur revient encore à l'époque moderne ${ }^{20}$. Outre ces ouvrages à caractère plutôt linguistique ou

12 Cf. aussi deux bibliographies consacrées à ce sujet: N[ino] BRIAMONTE, Saggio di bibliografia sui problemi storici, teorici e pratici della traduzione, Naples 1984; K[arl] R[ichard] BAusch et al., The Science of Translation. An Analytical Bibliography, Tübingen 1970; cf. de même certains numéros de la revue: Meta. Journal des traducteurs, en particulier le numéro spécial: La traduction juridique, vol. 24/1 (1979).

13 Henti Van Hoof, Petite histoire de la traduction en Occident, Louvain-la-Neuve 1986.

14 Georges Mounin, Die Übersetzung. Geschichte, Theorie, Anwendung, Munich 1967.

15 George STEINER, After Babel. Aspects of Language and Translation, New York, Londres 1975.

${ }^{16}$ L. G. KelLy, The True Interpreter. A History of Translation Theory and Practice in the West, Oxford 1979. Malgré le titre, c'est une initiation systématique aux aspects théoriques et pratiques de la traduction plutôt qu'une »histoire « de celle-ci (la bibliographie, p. 253274 , est utile).

17 Edmond CARY, La traduction dans le monde moderne, Genève 1956.

18 Paul Herbert LARWILL, La théorie de la traduction au début de la Renaissance (d'après les traductions imprimées en France entre 1477 et 1527), Munich 1934.

19 Cf. Karl THIEME, Alfred HeRmanN, Edgar GLÄSSER, Beiträge zur Geschichte des Dolmetschens, Munich 1956 (Schriften des Auslands- und Dolmetscherinstituts der Johannes-Gutenberg-Universität in Germersheim, 1).

20 Cependant, on a parfois des difficultés à saisir leur rôle puisque, malgré leur importance, les interprètes étaient en général considérés comme faisant partie du personnel subalterne des délégations - ils ne comptent que rarement parmi les hauts fonctionnaires d'un État. À 
littéraire, il y a encore le très beau livre de Philipp Heck sur la traduction au haut Moyen Âge ${ }^{21}$, auquel on a justement reproché de ne traiter que de la traduction judiciaire, tellement »traduction« semble équivaloir, dans les esprits, à »traduction littéraire«.

Suivant l'exemple des médiévistes et des historiens de l'Antiquité, l'histoire des langues et de la traduction diplomatiques aux $\mathrm{XVII}^{\mathrm{e}}$ et $\mathrm{XVIII}^{\mathrm{e}}$ siècles doit tenir compte de la fonction politique, non seulement des interprètes, mais aussi des traducteurs de textes politiques et de leurs traductions; à propos des versions françaises des traités de Westphalie, on peut souligner le souci du pouvoir politique de contrôler de près l'édition des traités internationaux ${ }^{22}$, en imposant d'une part une censure rigoureuse ${ }^{23}$, et en favorisant d'autre part leur publication par les »imprimeurs et libraires ordinaires du Roi« ou dans la »Gazette de France «, qui était non seulement un journal hebdomadaire, mais aussi une sorte de >Journal officiel de l'Ancien Régime et l'organe primordial de la publication de documents officiels en France, au moment de la conclusion des traités de Westphalie ${ }^{24}$. Un éditeurlibraire éminent, Frédéric Léonard, se trouvait même pourvu de privilèges extraordinaires qui lui permettaient de publier seul les traités, dans leur version originale et dans leur version française, pendant vingt ans. En effet, les langues (dont le choix dans la négociation diplomatique peut entraîner des conséquences politiques et juridiques très précises, comme nous allons le voir) et la traduction ont une dimension et une importance politiques qui ne sont pas limitées à un contexte historique concret, mais que toutes les époques ont connues, d'une manière plus ou moins aiguë; cependant, aux XVII et $\mathrm{XVIII}{ }^{\mathrm{e}}$ siècles, ce problème acquiert une importance particulière, parce que de l'avis même des contemporains il s'agissait d'une période de transition 25 .

Certes, certains historiens ne négligent pas les langues et la traduction à l'époque moderne; saluons à ce propos »Espions et ambassadeurs au temps de Louis XIV «, par Lucien Bély, qui les évoque, à l'occasion du congrès d'Utrecht, dans un chapitre consacré aux »Langues de la diplomatie ${ }^{26}$, et le manuel d'histoire des relations internationales publié récemment par Claire Gantet ${ }^{27}$. Sur les langues dans la diplomatie de Louis XIV, nous avons aussi la très belle étude de Camilles-

l'époque moderne, Madame de La Fayette traitait d'ailleurs les traducteurs de »domestiques «, Montesquieu n'était guère bienveillant non plus à leur égard, cf. MouNIN, Übersetzung, p. 9, 23 et 36.

2) Philipp HECK, Übersetzungsprobleme im frühen Mittelalter, Tübingen 1931.

22 Cf. BRAUN, Traductions.

23 Cet aspect est aussi mis en relief par Claire GANTET, Guerre, paix et construction des États, 1618-1714, Paris 2003 (Nouvelle histoire des relations internationales, 2), p. 316.

${ }^{24}$ Cf. BRAUN, Die »Gazette de France«; cf. aussi notre réédition des traités de Westphalie d'après leur version publiée dans la "Gazette «: Guido BRAun, Antje OsCHMANN, Konrad RePGEN (éd.), Acta Pacis Westphalicae, série III, section B: Verhandlungsakten, vol. 1: Die Friedensverträge mit Frankreich und Schweden, t. 2: Materialien zur Rezeption, Münster 2007 (APW III B 1/2).

25 Voir ci-dessous, le témoignage de Frédéric-Charles Moser.

${ }^{26}$ BÉLY, Espions, p. 450-455.

${ }^{27}$ Cf. GANTET, Guerre, paix et construction, en particulier p. 313-320. 
Georges Picavet ${ }^{28}$. En ce qui concerne l'influence française sur l'Europe au XVIII' siècle, on pourra bien évidemment se reporter à l'ouvrage fondamental de Marc Fumaroli29.

En revanche, Milos Vec, dans son histoire de la »science« du cérémonial, parue en $1998^{30}$, néglige quasi complètement les aspects linguistiques. Heureusement, il y a néanmoins des travaux sur les traductions de certains grands juristes du XVII ${ }^{e}$ siècle: le très bel ouvrage de Sieglinde Othmer sur les traductions françaises des ouvres de Pufendorf par Barbeyrac ${ }^{31}$ et l'article de Marcel Thomann sur celles de Grotius ${ }^{32}$. L'impact de ces traductions paraît énorme; selon Thomann, Montesquieu, Voltaire, Rousseau et les Encyclopédistes n'ont connu Grotius que par ses versions françaises. Pourtant, la grande synthèse fait encore défaut: il n'y a aucune histoire universelle des langues diplomatiques ni de la traduction ${ }^{33}$. Alexander Ostrower ne s'est acquitté que partiellement de cette tâche; en effet, cet auteur cherche à donner une étude d'ensemble de l'histoire des langues diplomatiques, depuis l'Antiquité jusqu'au $\mathrm{XX}^{\mathrm{e}}$ siècle, mais avance des idées très discutables $^{34}$.

Pour ce qui est de la France, on peut se référer à l'excellente »Histoire de la langue française « rédigée par Ferdinand Brunot ${ }^{35}$, qui a un intérêt certain pour l'histoire diplomatique; en fait, celui-ci consacre aussi plusieurs chapitres aux langues de la diplomatie et fait preuve d'une connaissance des sources qui est rare chez les linguistes, puisque Brunot est allé consulter des documents originaux au Quai d'Orsay. La question des langues diplomatiques et du rôle du français est aussi abordée par Henriette Roumiguière ${ }^{36}$. Cette contribution, à part quelques remarques sur le XVIe siècle et la première moitié du XVIIe, se concentre sur la période qui va de 1648 à 1925; malgré une base documentaire assez fragile, l'auteur en arrive à des conclusions tout à fait recevables, insistant notamment sur la longévité du latin, qui perdure comme langue diplomatique jusqu'au XVIII' siècle et

28 Camille-Georges PICAVET, Le français et les langues étrangères dans la diplomatie au temps de Louis XIV, dans: Revue des sciences politiques 51 (1928), p. 578-592.

29 Cf. Marc Fumaroli, Quand l'Europe parlait français, Paris 2003.

30 Milos VEC, Zeremonialwissenschaft im Fürstenstaat. Studien zur juristischen und politischen Theorie absolutistischer Herrschaftsrepräsentation, Francfort/M. 1998.

31 Sieglinde C. OTHMER, Berlin und die Verbreitung des Naturrechts in Europa. Kultur- und sozialgeschichtliche Studien zu Jean Barbeyracs Pufendorf-Übersetzungen und eine Analyse seiner Leserschaft, Berlin 1970 (Veröffentlichungen der Historischen Kommission zu Berlin beim Friedrich-Meinecke-Institut der Freien Universität Berlin, 30).

32 Thomann, Traductions.

33 Cf. Mounin, Übersetzung, p. 22.

34 Il a tendance, en particulier, à généraliser des exemples dont le caractère représentatif n'est pas attesté, cf. Alexander OsTrowER, Language, Law, and Diplomacy. A Study of Linguistic Diversity in Official Relations and International Law, 2 vol., Philadelphie 1965.

35 Ferdinand BRUNOT, Histoire de la langue française des origines à nos jours, nouvelle édition, 13 vol. en 20 t., Paris 1966-1968 (première édition: Paris 1906-1948).

36 Henriette RoumigulÈrE, Le français dans les relations diplomatiques, dans: University of California Publications in Modern Philology XII (1925-1926), p. 259-340. 
à l'essor du français à partir de la fin du XVII ${ }^{e}$ siècle, dû à la prépondérance politique de la France et au prestige de sa société et de sa littérature 37 .

Les origines de l'emploi des langues et de la traduction entre des populations linguistiques différentes remontent à la période préhistorique ${ }^{38}$; si elles sont par conséquent inconnues, nous connaissons leur histoire depuis les premières civilisations ayant disposé d'une forme d'écriture ${ }^{39}$. La traduction est donc un phénomène bien connu dans les sociétés antiques. Ce sont en particulier les Romains qui développent toute une réflexion systématique autour de l'art de traduire, puisque leur littérature est née de la traduction ${ }^{40}$. D'après Mounin, c'est aussi à Rome que l'on peut saisir la première initiative politique de traduction: en 146 avant Jésus-Christ, le sénat ordonna que le traité du Carthaginois Mago sur l'agriculture fût traduit en latin ${ }^{41}$. Les auteurs chrétiens de l'Antiquité tardive, se penchant sur les problèmes de la traduction de la Sainte Écriture, poursuivent cette tradition, et la transmettent, en la modifiant, au Moyen Âge ${ }^{42}$. Dans les sociétés médiévales, l'effort de christianisation impliquait toujours un effort de traduction ${ }^{43}$; la tâche était de rendre compréhensible les textes sur lesquels cette religion du livre se fondait. C'est pour cela que les moines les traduisaient non seulement en Irlande et en Allemagne, mais aussi dans les pays slaves, c'est-à-dire partout où le christianisme devait être implanté. Or, à côté de cette traduction religieuse, il convient de ne pas oublier la traduction d'écrits scientifiques, politiques et philosophiques en langue arabe, qui passait souvent par les Juifs ${ }^{44}$. Mettons surtout en relief l'importance de la traduction juridique: car les toutes premières sources en langue française et en langue allemande sont des traductions du latin ${ }^{45}$, et des juristes se consacraient au problème de la formation des interprètes, qui devaient surtout servir dans les relations entre Occident et Orient, comme le fit Pierre Dubois, qui vécut sous Philippe le Bel, dans son traité »De recuperatione terrae sanctae ${ }^{46}$. C'est surtout dans l'Italie de Dante que l'on discute de manière systématique des problèmes de traduction. Le monde médiéval ne pouvait donc pas se limiter au seul

37 Cf. notamment ibid., p. 261, 331.

38 Cf. P[aul] PradiER-FoDÉRÉ, Cours de droit diplomatique à l'usage des agents politiques du Ministère des Affaires étrangères des États européens et américains, 2 vol., Paris ${ }^{2} 1899$, t. II, p. 327: "On a négocié sans doute depuis aussi longtemps qu'il existe des sociétés qui ont des intérêts à discuter«.

${ }^{39}$ Le fait que jusqu' au XVIII e siècle, en français, le mot »truchement «, d'origine assyrienne, désigne l'interprète s'explique par la culture de la traduction, qui était très développée chez les Assyriens, cf. Mounin, Übersetzung, p. 23.

40 Ibid.

${ }^{41}$ Cf. ibid., p. 192, n. 17.

42 Cf. Valéry LaRbaud, Sous l'invocation de saint Jérôme, Paris 1986 (premières éditions: $1945,1946)$.

43 Comme dit Mounin: »Christianiser veut toujours dire traduire « (»Christianisieren heißt immer übersetzen «), MouNIN, Übersetzung, p. 25.

44 Cf. le bilan de recherches publié par D. M. Dunlop, The Work of Translation at Toledo, dans: Babel 6 (1960), p. 55-59.

45 Cf. Mounin, Übersetzung, p. 26.

46 Cf. ibid., p. 192, n. 22. 
usage du latin ${ }^{47}$. C'est pourquoi l'on retenait que les princes devaient en principe parler plusieurs langues. Notons que la Bulle d'or, au chapitre XXXI, obligea les électeurs du Saint Empire romain germanique à apprendre à leurs enfants, outre l'allemand, le latin, l'italien et le tchèque ${ }^{48}$.

Or, dans l'Europe moderne, un changement fondamental s'opère au cours duquel les négociations temporaires et occasionnelles connues des sociétés antiques et médiévales se transforment successivement en représentations diplomatiques permanentes et institutionnalisées, accentuant les contacts entre groupes linguistiques différents, et intensifiant l'effort de traduction. C'est la véritable naissance de la diplomatie.

$\mathrm{Au} \mathrm{XVI}^{\mathrm{e}}$ siècle, on peut s'apercevoir d'un essor des langues vernaculaires qui ne cesse de s'accentuer, bien que l'usage du latin ne disparaisse point ${ }^{49}$. Ce dernier reste en effet, pendant toute la Renaissance, la langue commune à toute la chrétientée ${ }^{50}$. Malgré la persistance du latin comme lingua franca, Joycelyne G. Russell pense que les problèmes de compréhension liés à ce multilinguisme de la Renaissance conduisaient à une véritable tour de $\mathrm{Babel}^{51}$. Il est vrai que l'essor

47 Pourtant, ni la théorie ni la pratique de la traduction n'avaient encore atteint le niveau de la Renaissance. Pour la traduction au Moyen Âge cf, aussi en général Hans J. VERMEER, Das Übersetzen im Mittelalter (13. und 14. Jahrhundert), 3 vol., Heidelberg 1996 (Wissenschaft, 4); Geneviève Contamine (dir.), Traducteurs et traductions au Moyen Âge. Actes du colloque [de] Paris, 1986, Paris 1989; Jacqueline HAMESSE (dir.), Les traducteurs au travail. Leurs manuscrits et leurs méthodes. Actes du colloque international organisé par le »Ettore Majorana Centre for Scientific Culture (Erice, 30 septembre - 6 octobre 1999), Turnhout 2001 (Fédération internationale des instituts d'études médiévales. Textes et études du Moyen Âge, 18); EAD., Marta FATTORI (dir.), Rencontres de philosophie médiévale - Traducteurs et traductions de l'Antiquité tardive au XIVe siècle. Actes du colloque, 1990, Louvain-la-Neuve 1990; Ch. M. TERnEs (dir.), avec la collaboration de M. MunD-DoPCHIE, Méthodologie de la traduction: de l'Antiquité à la Renaissance. Actes du colloque de Luxembourg, Luxembourg 1994 (Centre universitaire du Luxembourg. Département des Lettres. Études classiques, 4). 48 Dans l'original, on lit $\gg$ Sclavica lingu[a] $\ll$. La Bulle d'or précisait que cet apprentissage des langues était non seulement utile mais nécessaire, puisque ces langues étaient fréquemment employées dans l'Empire et surtout dans le maniement des affaires politiques: $» c u m$ illud non solum utile, ymo ex causis premissis summe necessarium habeatur, eo quod ille lingue ut plurimum ad usum et necessitatem sacri Romani imperii frequentari sint solite et in hiis plus ardua ipsius imperii negocia ventilentur «, Konrad MüLLER (éd.), Die Goldene Bulle Kaiser Karls IV. 1356. Lateinischer Text mit Übersetzung, Berne ${ }^{3} 1970$ (Quellen zur Neueren Geschichte, 25), p. 98.

49 Cf. Joycelyne G. RusSELL, Diplomats at Work. Three Renaissance Studies, Phoenix Mill et al. 1992, en particulier l'introduction, p. XV-XVII, ici p. XVI, et le premier essai, intitulé: »Language: A Barrier or a Gateway?«, p. 1-50, ici p. 3; cf. aussi (quoique moins précis sur certains points): John HaLE, La civilisation de l'Europe à la Renaissance, [Paris] 1998, ici p. 149-170.

50 Cf. RuSSELl, Diplomats at Work, p. 3: »In the Renaissance period Latin was the common linguistic currency of Christendom «; pour le latin de la Renaissance, voir également Eckhard KESSLER, Zur Bedeutung der lateinischen Sprache in der Renaissance, dans: R. J. SCHOECK (dir.), Acta Conventus Neo-Latini Bononiensis. Proceedings of the Fourth International Congress of Neo-Latin Studies, Bologna 1979, Binghamton/New York 1985 (Medieval \& Renaissance Texts \& Studies, 37), p. 337-355.

51 Selon RusselL, la compréhension mutuelle des personnes n'était qu'un idéal, la réalité 
des langues vernaculaires se manifestait particulièrement dans les domaines de l'administration, de la justice et de la diplomatie ${ }^{52}$. Un ambassadeur était censé connaître avant tout le latin, de même qu'un ministre d'État; les connaissances linguistiques réelles des diplomates pouvaient être fort différentes ${ }^{53}$. Un ambassadeur allant en Allemagne avait absolument besoin de parler latin; les négociations entre la France et l'Allemagne se faisaient en général en latin, en certaines occasions en langue vernaculaire, à l'aide d'interprètes. Pour les princes, la connaissance du latin était souhaitable, sans qu'elle fût de rigueur ${ }^{54}$; si tous les princes ne maîtrisaient pas parfaitement le latin, certaines princesses faisaient preuve d'un latin excellent ${ }^{55}$. L'essor des langues vernaculaires rendait nécessaire le développement de nouvelles terminologies dans le domaine des sciences et lettres qui jusqu'alors avaient été exclusivement enseignées en latin (cela était en particulier vrai pour la jurisprudence et le droit). Russell constate qu'au XVIe siècle le français fut déjà la seconde lingua franca ${ }^{56}$. L'allemand n'étant en général pas connu dans les pays méridionaux et peu connu en France, les ambassadeurs étrangers envoyés dans le Saint-Empire négociaient le plus souvent en latin, mais quelquesuns d'entre eux parlaient quand même la langue du pays ${ }^{57}$.

La traduction contribue à la formation des langues nationales; en Allemagne, en Bohême et en Angleterre, les versions de la Bible deviennent des modèles exerçant une influence majeure sur l'histoire de ces langues. À cela s'ajoute une réflexion théorique sur la bonne traduction: dans ce domaine, c'est encore Luther, grand traducteur de la Bible (1522-1534), qui domine la discussion avec son traité »Sendbrief vom Dolmetschen «58. En France, Étienne Dolet fixe les règles d'une bonne traduction ${ }^{59}$; l'»Art poétique français ", de Thomas Sébillet, en 1548; la »Deffense et illustration de la langue françoise«, de Du Bellay; Montaigne, puis, en 1661, Gaspard de La Tende, sieur de l'Estang, dans son "Art de traduire", sont autant d'autres protagonistes du débat sur la traduction qui a lieu en France ${ }^{60}$.

étant au contraire marquée par une profonde incompréhension: cf. EAD., Diplomats at Work, p. 1.

52 Cf. Mounin, Übersetzung, p. 30-31.

53 Cf. RuSSELl, Diplomats at Work, p. 4-5 et p. 17-20.

$54 \mathrm{Cf}$. ibid., p. 5, 7-17 et 20-21. Dans cet exposé très instructif sur les langues diplomatiques au XVIe siècle, nous sommes pourtant obligés de relever une omission: en effet, la Bulle d'or enjoignit aux électeurs de l'Empire d'apprendre également l'italien à leurs enfants, à côté des langues nommées par Russell.

55 Cf. ibid., p. 42, n. 7: l'auteur rappelle aussi à plusieurs reprises les excellentes connaissances linguistiques d'Élisabeth $\mathrm{I}^{\mathrm{re}}$ reine d'Angleterre.

56 Cf. ibid., p. 4 et 30.

57 Cf. ibid., p. 39-41.

58 Cf. Catherine BocQueT, L'art de la traduction selon Martin Luther: ou lorsque le traducteur se fait missionnaire, Arras 2000, qui contient en appendice le texte du »Sendbrief «.

59 Cf. MOUNIN, Übersetzung, p. 31-33; Valerie WoRTH, Practising translation in Renaissance France. The example of Etienne Dolet, Oxford 1988. Cf. également Hans J. VERMEER, Das Übersetzen in Renaissance und Humanismus (15. und 16. Jahrhundert), 2 vol., Heidelberg 2000 (Wissenschaft, 6).

60 Cf. MounIN, Übersetzung, p. 33-38. 
Ce débat et la pratique de la traduction, notamment les versions calvinistes de la Bible, ne sont pas sans répercussions sur la politique; c'est pourquoi l'on a pu dire que »les guerres de religion s'accompagnent d'une guerre des traductions « ${ }^{61}$. Rompant avec la versio médiévale, la Renaissance renoua avec la véritable traduction de Cicéron et de saint Jérôme, et prit en considération les différences culturelles qui pouvaient exister entre la langue originale et la version ${ }^{62}$. Toutefois, comme le Moyen Âge, la Renaissance accepte la supériorité du grec et du latin. La traduction de la langue ancienne sert à perfectionner la langue moderne ${ }^{63}$. Puis, la querelle des Anciens et des Modernes vint ébranler la domination du latin, et le classicisme, que nous entendons ici comme l'époque qui va de 1636 à 1789, produisit un type de traduction qualifiée de "belle infidèle«, qui domina largement la pratique de la traduction en France et au-delà ${ }^{64}$ : les traducteurs des lois et des traités de paix suivirent-ils cet idéal de traduction ou conservèrent-ils littéralement le »mot sacramental « qu' ils trouvaient dans les actes originaux? Très certainement, le décalage qui existait entre le goût du public et la nature des textes qu'ils devaient traduire compliquait énormément leur tâche. De toute façon, il faudra retenir que la traduction littérale ne passait pas pour la meilleure traduction dans la période que nous étudions.

Dans le Saint-Empire comme en France, des règlements nouveaux régissent l'emploi des langues au cours du premier XVIe siècle: tandis que la capitulation de Charles Quint accorde, en 1519, aux langues latine et allemande le statut de langues officielles ${ }^{65}$, non pas pour évincer l'une ou l'autre de ces langues mais pour éviter le français et l'espagnol de Charles Quint et de son entourage, l'ordonnance de Villers-Cotterêts, de François Irer66, impose, en 1539, l'emploi du fran-

61 Ibid., p. 32: „Wenn man so will, geht mit den Religionskriegen ein Krieg der Übersetzungen einher «.

62 Cf. ibid., p. 34.

63 Pour la traduction des auteurs grecs et latins en France aux XVII' et XVIII' siècles, cf. Justin Bellanger, Histoire de la traduction en France (auteurs grecs et latins), Paris 1903, p. 29-79.

64 Par contre, en Allemagne, les traducteurs manifestaient un plus grand respect de l'original, de sorte qu'on peut parler d'une profonde divergence entre l'idéal de la traduction en France et celui qui a existé en Allemagne, surtout au XVIIIe siècle; cf. Werner Krauss, Zur Theorie und Praxis des Übersetzens im Frankreich und Deutschland des 18. Jahrhunderts, dans: Beiträge zur Romanischen Philologie 12 (1973), p. 387-392, en particulier p. 389 390.

65 La capitulation de Charles Quint a été publiée dans: Emst WALDER (éd.), Kaiser, Reich und Reformation 1517 bis 1525. Die 95 Thesen Luthers 1517; die Wahlkapitulation Karls V. 1519; das Wormser Edikt 1521; die zwölf Artikel der Bauern 1525, Berne, Francfort/M. ${ }^{4} 1974$ (Quellen zur Neueren Geschichte, 3), p. 25-34, ici p. 29. La Bulle d'or n'avait par contre pas fixé les langues officielles de l'Empire bien qu'elle eût obligé les princes électeurs à apprendre à leurs fils ou successeurs outre l'allemand, le latin, l'italien et le tchèque.

66 Ordonnance sur le fait de la justice, Villers-Cotterêts, août 1539, enregistrée au parlement de Paris le 6 septembre, dans: [Athanase-Jean-Léger] JouRDAN, DECRUSY, [François-André] ISAMBERT (éd)., Recueil général des anciennes lois françaises, depuis l'an 420 jusqu'à la Révolution de 1789 [...], 29 vol., Paris 1821-1833, ici vol. XII: 1514-1546, no 188, p. 600-640 (sur l'usage des langues: $\S \S[110]$ et [111], p. 622-623). 
çais dans le royaume, au détriment du latin ${ }^{67}$. C'est-à-dire qu'à l'époque même où la France commence à renoncer au latin, le Saint-Empire pérennise son usage. Mais ni en France ni en Allemagne il n'y a aucune politique linguistique systématique et réfléchie. Qu'en est-il des langues parlées par les souverains?

À l'aube des Temps modernes, l'Allemagne fut gouvernée par un empereur qui, d'après Wolfgang Reinhard, était un homme cultivé et s'intéressant aux beaux-arts et à la littérature, et qui parlait un latin simple, à l'usage quotidien, et cinq langues étrangères vivantes: Maximilien ler68. Selon le même auteur, son successeur, Charles Quint, parlait le français comme langue maternelle, n'apprenant l'espagnol qu'assez tardivement et ne sachant jamais vraiment parler un Hochdeutsch correct ${ }^{69}$. De plus, son latin était assez rudimentaire ${ }^{70}$. En ce qui concerne le frère de Charles Quint, Ferdinand I ${ }^{\text {er }}$, qui le représentait dans l'Empire pendant son absence et lui succéda, il ne jouit pas au début d'une bonne réputation en Allemagne, car il ne parlait pas l'allemand ${ }^{71}$.

Or, il convient bien de souligner la situation linguistique particulière qui en résulta, puisqu'elle revêt un intérêt majeur pour notre question. En effet, si Charles Quint parlait comme langue maternelle le français ou, comme il disait lui-même, le bourguignon, et que la langue maternelle de son frère était l'espagnol, les deux monarques correspondaient en général en français ${ }^{72}$. C'est-à-dire qu'en parlant des affaires concernant le Saint-Empire, l'empereur et le roi des Romains se servaient de la langue française. Pour cette raison, on doit supposer que le vocabulaire français désignant les réalités constitutionnelles du Saint-Empire fut assez précis au cours du premier XVIe siècle pour que les deux monarques fussent en mesure de s'exprimer de manière pertinente dans cette langue.

${ }^{67}$ En principe, le latin fut banni des actes administratifs et judiciaires. Nous n'entrerons pas ici dans une discussion sur la signification de cette ordonnance dont l'interprétation reste difficile.

68 Selon l'expression de Reinhard, que nous avons paraphrasée ci-dessus, il était »ein gebildeter und künstlerisch interessierter Mensch, der Gebrauchslatein und fünf lebende Fremdsprachen beherrschte und als belesen gelten darf «, cf. Wolfgang REINHARD, Probleme deutscher Geschichte, 1495-1806. Reichsreform und Reformation, 1495-1555, Stuttgart ${ }^{102001}$ (Gebhardt. Handbuch der deutschen Geschichte, 9), p. 236.

69 Cf. ibid., p. 257.

70 Cf. Pierre Chaunu, Michèle Escamila, Charles Quint, Paris 2000, p. 31, 58 et 161.

71 Cf. Reinhard, Probleme, p. 275.

72 Pour les langues parlées par Charles Quint et son frère ainsi que dans leur entourage, cf. généralement Chaunu, Escamilla, Charles Quint, en particulier p. 13, 17-18, 25, 30-31, $38,46,48-49,51,74-76,78-81,94-97,101,105,111-112,114,117,123,125-127,135$, 148, 238; Jean-Pierre SoISSON, Charles Quint, Paris 2000, en particulier p. 14, 27, 41-42, 67 (erreur: Charles Quint pouvait utiliser non seulement l'allemand, comme le prétend Soisson, mais aussi le latin dans les affaires concernant le Saint-Empire), 69, 85, 87, 111, 136, 157, $167,171,207,251,278,289,296,299-301,320$. 


\section{L'emploi des langues et la traduction dans la diplomatie depuis le XVIIe siècle: l'état des connaissances}

Pour ce qui est du XVII siècle, on peut noter que, heureusement, le problème des langues est bien pris en considération dans certains ouvrages de la nouvelle histoire diplomatique: saluons tout particulièrement l'étude très instructive de Claire Gantet sur "Guerre, paix et construction des États « de 1618 à 171473. Au XVII ${ }^{e}$ siècle, en France, comme dans la plupart des pays d'Europe, il n'y avait pas de correspondance entre l'identité linguistique et l'unité ou la domination politique $^{74}$; Gantet énumère douze langues régionales et étrangères qui étaient parlées au royaume de France ${ }^{75}$. Selon elle, l'ordonnance de Villers-Cotterêts, promulguée en 1539, avait touché bien plus l'usage du latin que les patois ${ }^{76}$. En ce qui concerne les relations internationales, elle note: »L'argument linguistique n'est guère employé à des fins politiques «, même si on avait bien saisi l'importance des langues pour la culture et le politique. Toutefois, même un ministre d'État comme Mazarin, originaire d'Italie, ne commença, selon Gantet, à rédiger ses notes en français qu'à partir de 1648. Les milieux auliques étaient cosmopolites et polyglottes: au Louvre, on parlait, outre le français, l'italien et l'espagnol ${ }^{77}$. C'est un aspect important qui éclaira nos propos sur les congrès de paix et les missions diplomatiques entre 1643 et 1756; en effet, les négociateurs y retrouvaient les mêmes réalités (cosmopolitisme et multilinguisme) qui correspondaient à leurs expériences en France.

Il en va de même pour la plupart des Allemands qui partaient en mission en France et qui connaissaient ces phénomènes à travers leurs séjours à la cour impériale de Vienne ou aux différentes cours princières allemandes. En Allemagne, la traduction de la Bible par Luther avait propagé le Hochdeutsch comme dialecte appelé à devenir la langue du pays tout entier; au XVII ${ }^{\mathrm{e}}$ siècle, le Hochdeutsch était enseigné aux jeunes princes allemands ${ }^{78}$. Le Saint-Empire conservait néanmoins ses nombreux dialectes et n'était pas exclusivement germanophone, mais englobait aussi des territoires où l'on parlait le tchèque, l'italien et d'autres langues.

Ces contributions de la nouvelle histoire diplomatique enrichissent notre connaissance de l'histoire de la traduction et des problèmes linguistiques dans les

73 GANTET, Guerre, paix et construction.

74 Cf. ibid., p. 313. Parfois, il y a quand même, au moins depuis le XVIe siècle, une réflexion sur la correspondance entre frontière linguistique et frontière étatique; voir, par exemple, le traité de Chambord, chez DuMONT, Corps universel, t. IV/3, p. 33; la question des langues diplomatiques et le problème langues/frontières sont aussi abordés par William James RoOSEN, The Age of Louis XIV. The Rise of Modem Diplomacy, Cambridge (Mass.) 1976, p. 54-55; Matthew Smith ANDERSON, The Rise of Modern Diplomacy, 1450-1919, Londres, New York 2001, p. 96-102.

75 Cf. GANTET, Guerre, paix et construction, p. 313.

76 Cf. ibid., p. 314.

77 Cf. ibid., p. 314 (citation) et 315.

78 Cf. Jean MEYer, L'éducation des princes du XVe au XIX ${ }^{\mathrm{e}}$ siècle, Paris 2004, p. 128-129. 
relations entre les pays de langues différentes, et nous apportent de nombreux détails, ce qui est d'autant plus important que la traduction judiciaire et diplomatique apparaît comme un champ de réflexion extrêmement intéressant. En effet, l'importance du langage était aussi soulignée par des contemporains, tel La Maillardière: »Dans les stipulations d'un traité, le mot est sacramental«, écrivit celuici en $1778^{79}$.

Au XVII siècle, certains Français se sont intéressés aux langues parlées dans le Saint-Empire: c'est, entre autres, Théodore Godefroy qui nous en a laissé un très beau témoignage. D'abord, il constate que l'usage de l'allemand échappe à l'Allemagne; à cet égard, il faut noter que, comme une grande partie de ses contemporains, il considérait les autres langues germaniques comme des dialectes de l'allemand. En effet, Godefroy y inclut les langues scandinaves et l'anglais, dressant un tableau fidèle des régions où l'allemand ou ces langues germaniques furent parlées au premier XVIIe siècle ${ }^{80}$. Toutefois, Godefroy est bien conscient des différences fondamentales qui existent entre ces différents »Dialectes« germaniques; il compare les difficultés de compréhension qui en résultent à la situation linguistique qui existait alors en France, où les personnes parlant le français n'en comprenaient pas certains dialectes. Or, à part l'allemand, on parlait aussi d'autres langues dans les territoires qui faisaient partie du Saint Empire romain germanique, en particulier le français dans certaines régions occidentales, comme Godefroy ne manque pas de le souligner, s'avérant encore une fois un bon observateur de la situation réelle. En outre, il sait qu'en certaines régions de l'Empire, on parle des langues slaves; rappelons que c'est pour cette raison que la Bulle d'or avait enjoint aux électeurs, dès le XIVe siècle, d'apprendre la langue slave (le tchèque) à leurs enfants. Enfin, l'Empire comprenait des régions italophones ${ }^{81}$; pour cette raison, les jeunes princes électeurs durent apprendre, dès le XIVe siècle, la langue italienne. Godefroy, conseiller des ambassadeurs français au congrès de Westphalie, connaissait donc très bien la situation des langues parlées dans le Saint-Empire.

Qu'en fut-il des connaissances linguistiques des diplomates eux-mêmes, au XVII e siècle? Pour les maigres connaissances d'allemand des Français au XVII siècle, nous disposons de l'excellente étude de Paul Lévy ${ }^{82}$. Cependant, les

${ }^{79}$ Charles François Lefèvre DE LA MAILlARDIĖRE, Abregé dès principaux traités, conclus depuis le commencement du quatorzième siècle jusqu'à présent, entre lès différentes puissances de l'Europe [...], 2 vol., Paris 1778, ici t. I, p. V. Des auteurs du XIX ${ }^{\mathrm{e}}$ siècle font part du même jugement en ce qui concerne l'importance de chaque mot dans les documents de nature juridique ou diplomatique; cf. par exemple Pradier-FoDÉrÉ, Cours de droit diplomatique, t. II, p. 318. Ceci peut faire ressortir l'intérêt de la traduction pour l'histoire diplomatique et judiciaire; il faut insister surtout sur le fait que l'étude des langues ne doit pas se limiter à une énumération des langues parlées par les princes et les diplomates, mais qu'elle doit au contraire englober leur signification politique et culturelle.

$80 \mathrm{Cf}$. le chapitre $»$ Des diuerses Langues, qui sont en usage en L'Empire d'Alemagne $\ll$, dans MaLeTtKe, HanKe (éd.), Description, p. 266.

${ }^{81}$ Cf. ibid.

82 Paul LÉVY, La langue allemande en France. Pénétration et diffusion des origines à nos 
diplomates, en particulier ceux ayant effectué plusieurs missions dans l'Empire, connaissent parfois très bien l'allemand, comme l'envoyé français à la diète permanente de Ratisbonne, Gravel ${ }^{83}$. D'ailleurs, au congrès de Westphalie, la France envoya des représentants faisant preuve d'une parfaite maîtrise de la langue allemande, comme par exemple le comte d'Avaux et Théodore Godefroy ${ }^{84}$. Certes, en général, nous n'avons pas de documents rédigés en allemand par ces personnages, de sorte que, pour évaluer leurs connaissances linguistiques, nous devons faire confiance aux témoignages de leurs contemporains; mais il en va de même pour les autres participants au congrès de Westphalie ${ }^{85}$.

Or, cette bonne maîtrise des langues étrangères ne va pas encore de soi dans la diplomatie française au milieu du XVIIe siècle; on sait par exemple que le duc de Longueville, principal plénipotentiaire de la France à Münster, ne comprenant pas bien l'espagnol (si l'on en croit ses propres assertions), dut demander aux Espagnols de ne plus lui communiquer leurs projets de traités dans cette langue ${ }^{86}$. En 1650 , un négociateur français fut envoyé à Vienne; nous possédons l'historique de cette mission, la Relation politique de la négotiation du comte de Saujon $\aleph^{87}$, qui, malgré son titre, n'est pas véritablement une »relation«, mais l'ouvrage d'un historien anonyme. Bien que, selon l'auteur de cette »relation «, ce négociateur, le comte de Saujon, sût s'acquitter fort bien de sa tâche, il »ignoroit entièrement la

jours, 2 vol., Lyon, Paris 1950-1952 (Bibliothèque de la société des études germaniques, IV et VIII). Cf. également BraUN, Von der politischen zur kulturellen Hegemonie, p. 181-202 et 259-262 (bibliographie).

83 Pour les missions de Robert de Gravel comme plénipotentiaire français à Francfort et à Ratisbonne, voir AUERBACH, La France et le Saint Empire romain germanique; MALETTKE, Les relations entre la France et le Saint-Empire au XVII siècle, Paris 2001 (Bibliothèque d'histoire moderne et contemporaine, 5).

84 D'après IRSIGLER, d'Avaux parlait couramment le latin et l'allemand: cf. EAD., Einleitung, APW II B 1, ici p. LXVI; voir aussi Albert WADDINGTON, Le Grand Électeur Frédéric Guillaume de Brandebourg. Sa politique extérieure 1640-1688, vol. I (1640-1660), Paris 1905, p. 185; pour Godefroy, cf. MALETTKE, HANKE (éd.), Description.

85 Ainsi, nous connaissons la bonne maîtrise du français dont faisait preuve l'envoyé bavarois Krebs à travers le jugement du comte d'Avaux. En effet, celui-ci écrivit le 22 avril 1647 dans son mémoire adressé d'Osnabrück à Louis XIV: »C'est un homme de mérite, fort intelligent aux affaires d'Allemagne, et qui parle bien françois«; BRAUN, APW II B 5/2, document $n^{\circ} 237$, p. 1118. Pour Krebs, voir Anuschka TiSCHER, Dr. Johann Adolph Krebs von Bach zwischen dem Reich und Frankreich - ein elsässisches Schicksal am Ende des Dreißigjährigen Krieges, dans: Francia 26/2 (1999), p. 149-162.

86 Ce que les Espagnols acceptèrent; cf. l'extrait d'une lettre anonyme de Münster, 12 mars 1647, copie: IF, Coll. Godefroy 22 fol. 384-385, ici fol. 384.

87 Bibliothèque de l'Arsenal, ms. 4604 et 4605 . Pour la mission de Saujon et son contexte cf. aussi Christian BOUYER, La Grande Mademoiselle. Anne Marie Louise d'Orléans duchesse de Montpensier, Paris 1986, p. 137-167, en particulier p. 156-157; cf. aussi William James Roosen, The Ambassador's Craft: A Study of the Functioning of French Ambassadors under Louis XIV, thèse université de Berkeley (Californie) 1967, microfilm Ann Arbor (Michigan) 1969, p. 24-25; ID., The True Ambassador: Occupational and Personal Characteristics of French Ambassadors under Louis XIV, dans: European Studies Review 3 (1973), p. 121139, ici p. 129. 
langue allemande $^{88}$ et »alloit en un pays qui luy étoit tout affaict inconnu «89. On n'apprend pas comment Saujon sut surmonter l'obstacle linguistique, d'autant plus qu'il »ne sçavoit pas mesme bien parler l'italienne, qui estoit la seule qui pouvoit suppléer au deffault de l'autre [sc. la langue allemande] et en laquelle les ministres de 1'Empereur s'énonçoient assez passablement $\aleph^{90}$, et qu'on lui interdit, en outre, de se servir d'un interprète.

Généralement, la bonne connaissance de l'histoire et de la civilisation du pays où on envoyait un ambassadeur fut pourtant l'un des critères, sinon effectifs, du moins théoriques, de son choix. Dans un traité sur la charge de l'ambassadeur rédigé bien avant le congrès de Westphalie ${ }^{91}$, l'on exigeait qu'il dût »estre versé aux actions du monde, et principallement en celles de son pays, et de celuy où il est ambassadeur«. Et d'ajouter un catalogue de connaissances requises:

Et pour ce que la vie de l'homme est trop courte pour en attendre de l'expérience propre à la sufisance quy luy est nécessaire, il doit aussy estre versé en la lecture de touttes sortes d'histoires qu'il doit avoir leues avec jugement, pesant touttes les circonstances des actions quy y sont représentées, savoir la diversité des establissementz des Estatz, et les raisons sy faire ce peult de cette diversité, entendre le droict des limittes, représailles, les généalogies des princes, les prétentions des Roys sur les Estatz les uns des autres, leur force, leurs moyens, leurs alliances et leurs façons de vivre sans y rien obmettre ${ }^{92}$.

La connaissance du pays allait le plus souvent de pair avec la connaissance de sa langue; c'est ainsi que d'Avaux et Godefroy ne parlaient pas seulement l'allemand avec une aisance admirable, mais connaissaient aussi parfaitement le droit, l'histoire et les coutumes du pays.

Les capacités linguistiques des diplomates et des chancelleries des autres pays nous sont parfois connues à travers les ouvrages qui existent sur l'histoire de leur service diplomatique; notons par exemple les études tout à fait remarquables qui ont été consacrées à l'histoire de la diplomatie suédoise. Mais l'état des connaissances reste en général peu satisfaisant ${ }^{93}$. Par conséquent, la question se pose de savoir où l'on peut se renseigner sur les usages linguistiques du XVII ${ }^{\mathbf{e}}$ siècle s'il n'y a pas d'ouvrage moderne qui satisfasse tous nos besoins. À défaut de travaux

${ }^{88}$ Bibliothèque de l'Arsenal, ms. 4604 fol. 6'.

89 Ibid., fol. 7.

90 Ibid., fol. 6'-7; la cour de Vienne fut pourtant un lieu où on savait parler l'italien non seulement »assez passablement «, mais aussi souvent parfaitement.

${ }^{91}$ Bibliothèque de l'Arsenal, ms. 4601: »De la charge et administration de ceux qui doibvent aller pour ambassadeurs ou agents vers quelques princes ou Estatz que ce soit, tant pour maintenir la grandeur et dignité de leur maistre que pour s'acquérir la bienveillance entre les peuples avec lesquelz ils ont à négotier, ensemble de la façon de se gouverner aux traictez qu'il convient journellement faire avec les princes et Estatz de quelque condition qu'ilz soient $\ll$.

92 Ibid., fol. 3-3'.

93 Parmi les publications récentes les plus importantes, signalons aussi Thomas NICKLAS, Matthias SCHNETTGER (dir.), Politik und Sprache im frühneuzeitlichen Europa, Mayence 2007 (Veröffentlichungen des Instituts für Europäische Geschichte Mainz, Abteilung für Universalgeschichte, cahier suppl. 71). Pour la Suéde, voir Carl-Fredrik PALMSTIERNA et al., Histoire de l'administration des Affaires étrangères de Suède, Uppsala 1940. 
du XIX $\mathrm{Xu}^{\mathrm{e}}$ ou $\mathrm{XX}^{\mathrm{e}}$ siècle, nous pouvons heureusement nous reporter à un excellent traité sur cette question, qui date du milieu du XVIIIe siècle: en effet, Frédéric-Charles Moser publia, en 1750, un »Traité des langues des Cours et des États européens«, rédigé en allemand et digne des plus grands éloges ${ }^{94}$. Étant donné les lacunes historiographiques, l'excellent traité de Moser devient une source sinon unique, du moins indispensable ${ }^{95}$. La valeur extraordinaire de cet ouvrage ne peut être appréciée que si on le compare aux travaux accomplis depuis sa parution, il y a deux siècles et demi. Moser comble donc une lacune importante. En effet, l'auteur a su donner le premier et l'unique aperçu lucide et compréhensible des usages linguistiques si embrouillés de la diplomatie européenne depuis la paix de Westphalie jusqu'au milieu du XVIII siècle; son traité constitue une excellente source pour restituer le quotidien linguistique de la diplomatie moderne. Nous ne résumerons pas en détail les résultats du travail de Moser. On peut cependant dire, après la lecture de cet ouvrage, que si la diplomatie de cette époque connaissait l'emploi du latin et de plusieurs langues modernes, parmi lesquelles prédominaient le français et l'italien, elle n'était pourtant pas une tour de Babel, puisqu'elle se fondait sur un système bien réfléchi. Surtout, l'on ne peut pas dire d'une manière générale que »la France n'avait pas de principes fermes quant à l'usage des langues dans les négociations des traités «96, mais, comme nous le verrons, il est vrai qu'elle ne disposait d'aucune >doctrine` en la matière.

Tous les pays d'Europe observaient en effet certains principes fondamentaux très précis quant à l'emploi des langues dans leurs relations avec les autres États. L'État tenant peut-être le plus fermement à ses principes fut, il est vrai, non pas la France, mais le Saint-Empire, même s'il ne faut pas oublier que certains de ses États territoriaux se montraient beaucoup plus disposés à accepter l'usage du français. Dans cette perspective, le traité de Rastatt passé entre la France et l'Empire en 1714, rédigé en latin, mais pourvu d'un article séparé rappelant pour l'avenir l'emploi obligatoire de la langue de Rome, n'est point une date cruciale qui marque la victoire du français sur le latin ${ }^{97}$. En effet, les choses ne changeront pas d'une manière fondamentale jusqu' au milieu du XVIII' siècle dans les relations franco-allemandes, et les deux pays veilleront à l'emploi de leurs langues officielles dans leurs rapports avec les autres États européens: la France, s'appuyant sur son rayonnement culturel qui faisait du français la première langue européenne, et le Saint-Empire, défendant - avec d'autres pays, comme la Pologne, la Suède ${ }^{98}$ et

94 Friderich Carl [voN] Moser, Abhandlung von den Europäischen Hof= und Staats=Sprachen, nach deren Gebrauch im Reden und Schreiben. Mit authentischen Nachrichten belegt, Francfort/M. 1750.

95 Cf. Guido Braun, Frédéric-Charles Moser et les langues de la diplomatie européenne (1648-1750), dans: Revue d'histoire diplomatique 113 (1999), p. 261-278.

96 BÉly, Espions, p. 450.

$97 \mathrm{Ce}$ jugement se trouve pourtant dans: Louis RÉAU, L'Europe française au siècle des Lumières, París 1938, p. 13. BÉLY rappelle plus prudemment l'article séparé de la paix de Rastatt: ID., Espions, p. 455.

98 Pour le latin en Suède au XVIIe siècle, voir l'article très instructif de Bo LINDBERG, Latein und Großmacht. Das Latein im Schweden des 17. Jahrhunderts, dans: Eckhard KESSLER, 
le Saint-Siège - l'usage du latin, sa deuxième langue officielle à côté de l'allemand depuis la capitulation impériale de Charles Quint (1519), et en même temps la langue ocuménique de l'Occident chrétien. Par ailleurs, la stipulation que la capitulation de Charles Quint contenait au sujet des langues, fut confirmée par les empereurs suivants; dans la capitulation de Ferdinand II, cette clause n'a pas échappé à Théodore Godefroy 99 .

Parfois, les autres pays n'en font pas moins les difficiles pour autant. Pourquoi ces batailles autour de la langue de la diplomatie? La réponse est simple, et elle explique toute la chaleur du combat: la langue est une marque de la souveraineté. Cela sert à comprendre l'assiduité (déjà relevée par Bäte, en 1948) avec laquelle les Hollandais, en quête de leur indépendance, parlaient leur propre langue au congrès de Westphalie ${ }^{100}$. C'est aussi pourquoi l'électeur de Saxe exigea que les lettres qui l'intéressaient en tant que roi de Pologne lui fussent adressées en latin, et non pas en allemand, langue pourtant admise dans la correspondance entre la Chancellerie impériale et cet électeur pour les lettres le concernant en qualité d'électeur du Saint-Empire. Les archives diplomatiques renferment bon nombre de mémoires sur l'usage observé entre la France et les principautés du Saint-Empire; les mémoires traitant du cérémonial en général accordent aussi une place de prédilection à cette question. Les villes d'Allemagne tenaient elles aussi à l'emploi du latin dans leurs relations avec la France ${ }^{101}$. Même dans les lettres de recommandation fournies à leurs commerçants au début du XVIIe siècle, les villes de Nuremberg et d'Augsbourg n'admirent pas le français à la place du latin, parce que, comme disait le conseiller nurembergeois Ölhafen, il nuirait à la réputation de ses maîtres d'écrire en langue française ${ }^{102}$.

Le résultat de ces prétentions fut le plurilinguisme de la diplomatie du XVIIe siècle, qui se perpétua au XVIII ${ }^{c}$, avec deux langues prépondérantes (d'abord le latin, puis le français) et une demi-douzaine de langues mineures: italien, espagnol, allemand, néerlandais, etc. De toute façon, avec le déclin du latin, au XVIIe siècle, commence, comme l'a très justement remarqué Henri-Jean Martin, le »temps des traductions «103. Les négociations quasi quotidiennes entre les puissances souve-

Heinrich C. KUHN (dir.), Germania latina - Latinitas teutonica. Politik, Wissenschaft, humanistische Kultur vom späten Mittelalter bis in unsere Zeit, 2 vol., Munich 2003 (Humanistische Bibliothek, série I: Abhandlungen, 54), t. I, p. 679-692.

99 Dans son résumé de cette capitulation, Godefroy relève que l'empereur y a promis de: "N'user en ses Lettres et Ordonnances d'autre Langue que de l'Alemande, ou de la Latine, excepté es lieux où autre Langue que l'Alemande est en usage«; MALETTKE, HANKE (éd.), Description, p. 97-99, ici p. 97.

$100 \mathrm{Cf}$. Ludwig BÄTE, Die Stadt Osnabrück während der Verhandlungen zum Westfälischen Frieden, dans: ID. (dir.), Der Friede in Osnabrück, p. 65-78.

${ }_{101}$ Pourtant, il convient toujours de nuancer; rappelons par exemple que la Saxe adopta au XVIIIe siècle le français comme langue officielle.

$102 »$ Weil meinen Herren in französischer Sprache zu schreiben nit reputierlich sein würde «, cité d'après Gerhard PFEIFFer, Die Bemühungen der oberdeutschen Kaufleute um die Privilegierung ihres Handels in Lyon, dans: Stadtarchiv Nürnberg (dir.), Beiträge zur Wirtschaftsgeschichte Nürnbergs, vol. 1, Nuremberg 1967, p. 407-455, ici p. 430.

103 Henri-Jean Martin, cité d'après WAQUET, Le latin, p. 10. 
raines et ce caractère polyglotte de la diplomatie rendirent inéluctable la traduction, qui devint ainsi l'un des défis majeurs des relations internationales. Outre l'ouvrage de Moser, nous disposons de très bonnes sources pour restituer ce quotidien linguistique de la diplomatie moderne ${ }^{104}$; cela est particulièrement vrai pour le congrès de la paix de Westphalie pour lequel la documentation à travers les sources imprimées est sinon exhaustive, du moins la plus riche de tous les congrès de paix qui se sont tenus aux Temps modernes. Avant d'aborder les problèmes concrets de la traduction des termes techniques du droit allemand en français, il sera indispensable de définir d'une manière plus précise le rôle des langues et de la traduction depuis le congrès de Westphalie dans les relations entre la France et l'Allemagne, afin de mieux comprendre le cadre politique et intellectuel dans lequel ces traductions ont été faites.

\section{La paix de Westphalie, le ius gentium et les langues des relations internationales au XVII ${ }^{e}$ siècle}

Le congrès de Westphalie représentait, sur le plan institutionnel, une véritable nouveauté dans la diplomatie européenne, puisqu'il fut le premier congrès multilatéral, sinternational si l'on ose dire, d'une telle ampleur ${ }^{105}$ : cent-neuf délégations y participèrent, représentant seize États européens et cent quarante principautés et villes d'Allemagne ${ }^{106}$.

Dans une lettre du 9 avril 1644 adressée à Loménie de Brienne, secrétaire d'État aux Affaires étrangères de Louis XIV, l'un des ambassadeurs français à Münster, Abel Servien, décrit ainsi le grand congrès:

Voycy $[. .$.$] une espèce de concile politicque où presque toutes les nations de l'Europe auront$ des députéz et où pour ne rien faire de préjudiciable de part ny d'aultre nous ne sçaurions prendre une meilleure règle pour nostre conduicte en matière de complimens que ce qui s'observe en la Cour de Rome. Nous avons creu que sy on ne choisit un modèlle pour s'attacher fortement, ou il fauldra se relascher partout, dont vous sçavez mieux la conséquence que

104 Par exemple, pour les négociations de la paix de Münster, le journal de Volmar, farouche opposant à l'emploi du français, lequel, si son collègue Nassau se laissait entraîner dans une conversation en langue française pendant les négociations entre Impériaux et Français, se mettait aussitôt à pratiquer le latin ou l'italien; ce journal, révélateur de nombreux aspects du congrès, est édité par PHILIPPE, FoERSTER, APW III C 2.

105 Si d'autres conférences, comme à Mantoue, en 1459, à Cambrai, en 1529, ou à CateauCambrésis, en 1559, avaient déjà fourni des occasions aux diplomates de différents pays de se rencontrer et de devoir négocier en langue étrangère, ces réunions avaient été de moindre ampleur; cf. sur l'importance de ces conférences pour l'histoire des langues diplomatiques, RUSSELL, Diplomats at Work, p. 17.

106 Soixante-six envoyés, qui représentaient parfois plusieurs états de l'Empire (ainsi, cent quarante états étaient représentés en Westphalie); vingt-sept envoyés chargés de soutenir des intérêts particuliers vinrent compléter ce »concile politique de l'Europe, où l'on constatait seulement l'absence de l'Angleterre, du tsar et de l'Empire ottoman; sur la structure et le mode de travail du congrès cf. Konrad REPGEN, Die Westfälischen Friedensverhandlungen. 
moy, ou faire des bigearreries [c'est-à-dire admettre des ambiguïtés] qui donneroient du contentement aux uns et du mescontentement aux aultres ${ }^{107}$.

En l'absence de précédent politique, le Saint-Siège devint ainsi, non seulement pour les Français ${ }^{108}$, mais aussi pour les autres délégations, une référence essentielle pour régler les relations entre les différents ambassadeurs, du moins à Münster, où siégeaient les puissances catholiques; il n'est donc pas étonnant d'y retrouver aussi les langues de Rome, le latin et l'italien, comme principales langues de la négociation.

L'importance des traités de Westphalie pour le développement du droit international a fait, parmi les historiens, l'objet d'évaluations diverses, parfois contradictoires ${ }^{109}$. On y a voulu voir, avec Robert Redslob, »le portique majestueux qui mène d'un monde à un autre«, ou, avec Max Huber, des actes qui »reconnaissent l'existence d'une communauté entre les États«; Louis Le Fur, par contre, suivi dans son jugement par Jean Rouvier, ne les considère que comme "ébauche d'une codification partielle du droit international « ${ }^{110}$. Des jugements plus récents viennent nuancer ce tableau ${ }^{11}$. Certes, on ne tranchera pas ici, du moins en ce qui concerne les questions de droit international. Mais il est certain que les traités de Westphalie ne marquent ni »l'éclatement définitif de l'empire« ni celui »de la société chrétienne «, comme prétend Rouvier. Les États catholiques de l'Europe, quoique soucieux de leur souveraineté, se sont en effet souvent soumis, après 1648, à la médiation du pape dans les différends qui les opposaient entre eux, et ont bien continué par là à appartenir à une société chrétienne qui ne se transformait point du jour au lendemain en une société laïcisée ${ }^{112}$; le vestige linguistique de la survie de cette communauté traditionnelle d'États est l'emploi persistant du latin dans les rela-

107 IRSIGLER, APW II B 1, document $n^{\circ} 37$, citation p. 68-69.

108 Pour la France, cette comparaison avec Rome devait acquérir une signification très concrète dans la mesure où Brienne ordonna effectivement, le 28 mai 1644, aux plénipotentiaires français d'observer à Münster le même cérémonial qu'à la cour du pape, ibid., document $\mathrm{n}^{\circ} 117$, p. 211-214, ici p. 212.

109 Les conditions politiques, militaires, juridiques, religieuses, économiques, culturelles et sociales du congrès, le détail du déroulement de ses négociations, ainsi que ses conséquences pour l'Allemagne, la France, la Suède et l'Europe en général ont toujours suscité, dès le XVIIe siècle, un très grand intérêt parmi les historiens, comme en témoignent les milliers de publications consacrées à son sujet jusqu'à nos jours; cf. DuCHHARDT (dir.), Bibliographie (jusqu'en 1994); si les jugements portés à ce sujet ne sont pas toujours homogènes, le problème du droit international semble bien se situer parmi les questions les plus litigieuses. La question de savoir si la paix de Westphalie a été une loi fondamentale de l'Europe après 1648 est abordée par Heinhard STEIGER, Der Westfälische Frieden - ein Grundgesetz für Europa?, dans: DUCHHARDT (dir.), Der Westfälische Friede, p. 33-80.

110 Pour les problèmes de droit public et les positions citées cf. Jean Rouvier, Naissance du droit international au XVII ${ }^{e}$ siècle, dans: XVII' siècle 58/59 (1963), p. 40-56.

111 Cf., par exemple, STEIGER, Der Westfälische Frieden; ScHILling, Konfessionalisierung und Staatsinteressen, p. 565-601.

112 Pour le problème en général, cf. Konrad REPGEN, Friedensvermittlung als Element europäischer Politik vom Mittelalter bis zur Gegenwart. Ein Vortrag, dans: ID., Dreißigjähriger Krieg und Westfälischer Friede, p. 799-816. 
tions >internationales < bien après le congrès de Westphalie, où la langue originelle de l'Occident chrétien fut l'instrument primordial de la communication.

Le véritable apport du congrès se perçoit non seulement dans le domaine des grands courants dans la philosophie et la théorie du droit qui ont marqué le XVII ${ }^{\mathrm{e}}$ siècle (ou dans celui de l'application de certains principes fondamentaux comme la liberté de la navigation), mais aussi à travers l'analyse des solutions que l'on a apportées à une infinité de problèmes pratiques qui ne s'étaient jamais posés jusque-là. Un de ces problèmes, certainement parmi les plus importants, quoique moins âprement discuté que les questions du cérémonial concernant la préséance, fut de s'accorder sur les langues de la négociation entre les représentants de tant de souverains et peuples différents, allant de la péninsule Ibérique à la Scandinavie, et d'élaborer, ensuite, une terminologie sinternationale ‘ propre à traduire les particularités du droit public des différents États représentés à Mïnster et à Osnabrück et reconnue par tous. C'était devenu une nécessité absolue dans la mesure où les relations entre les États européens ne pouvaient plus se régler par le seul langage de la féodalité. Aux problèmes linguistiques proprement dits s'ajoutèrent donc ceux de la traduction.

Toutefois, au sujet de la langue des diplomates au congrès de Westphalie, qui était l'instrument même de toutes leurs négociations, il n'est pas rare de trouver des idées erronées ${ }^{113}$. Néanmoins, il faut remarquer que Fritz Dickmann, dans sa grande monographie sur la paix de Westphalie, a résumé d'une manière très concise certains aspects de cette question et fourni un tableau assez lucide de la vie linguistique du congrès; c'est en tout cas la meilleure référence que l'on puisse trouver pour aborder ce problème, parmi les ouvrages historiographiques généraux. Cependant, l'unique page ${ }^{114}$ que Dickmann y consacre ne peut évidemment pas apparaître comme une solution satisfaisante, tant par son manque de détails et de précisions que par le silence gardé sur certaines contradictions; en outre, beaucoup d'explications sont insuffisantes. Si l'on peut entrevoir les contours du tableau, ses couleurs nous échappent.

En revanche, l'étude la plus détaillée du rôle du français, déjà évoquée, est celle de Ferdinand Brunot ${ }^{115}$. Outre Brunot, d'autres auteurs, comme Henriette Roumiguière ${ }^{16}$ et Alexander Ostrower ${ }^{117}$, reproduisent plus ou moins fidèlement les résultats de ses recherches, sans avoir consulté les sources. Par ailleurs, le constat que nous venons de dresser pour le congrès de Westphalie n'est pas un fait isolé; comme nous l'avons exposé ci-dessus, d'une manière générale, l'histoire des

113 Bäte a raison de souligner l'absence d'une langue commune pour toutes les négociations, le rôle du latin et la tentative des Néerlandais d'imposer leur langue; en revanche, il n'est pas tout à fait correct de dire qu'on refusa l'espagnol (d'ailleurs, pourquoi parle-t-il de »l'espagnol traditionnel«?), le suédois et le français - les choses sont plus compliquées -, cf. BÄTE, Die Stadt Osnabrïck, p. 69.

114 DickmanN, Der Westfälische Frieden, p. 214-215, avec les notes p. 547.

115 Cf. BRUNOT, Histoire, t. V, p. 393-401.

116 Cf. Roumiguière, Le français.

117 Cf. Ostrower, Language. 
langues et de la traduction diplomatiques reste à faire. Ces lacunes dans l'état des connaissances s'expliquent peut-être en partie par l'abondance des sources et par des obstacles linguistiques et terminologiques ${ }^{118}$. Pour éviter de fonder ses jugements sur des cas exceptionnels, il est en effet indispensable qu'un grand nombre de textes soient facilement accessibles, de sorte que notre propre étude n'aurait pas été possible sans les vingt-huit volumes des "Acta Pacis Westphalicae « publiés en quarante-et-un tomes jusqu'en 2009, d'autant que les éditions plus anciennes des actes du congrès de Westphalie reproduisent parfois des traductions sans attirer l'attention du lecteur sur ce fait, et peuvent par conséquent l'induire en erreur'119.

Aux lacunes historiographiques s'ajoute le fait que celui qui travaille sur l'emploi des langues et la traduction dans le monde moderne se heurte à certaines difficultés qui découlent, par exemple, du fait que le système des langues européennes n'est, jusqu'au XVIII' siècle, pas toujours décrit de la même façon qu'aujourd'hui; ainsi, le dictionnaire de Moréri de 1740 ne connaît que quatre langues: slave, germanique, latine et grecque; toutes les autres langues reconnues aujourd'hui comme telles y sont considérées soit comme des "dialectes" soit comme des "rejetons « du latin (dont le français) ou du grec ${ }^{120}$. Certaines langues n'y apparaissent même pas du tout, par exemple le néerlandais. Les dénominations que nous trouvons dans les sources peuvent donc différer des nôtres. De la même manière, pour ne s'en tenir qu'aux seules sources en langue française du congrès de Westphalie, on peut par exemple constater qu'elles parlent de la langue allemande quand il s'agit effectivement du suédois, considéré comme un dialecte de l'allemand, ou disent flamand là où nous mettrions aujourd'hui néerlandais, langues que l'on ne distingue pas encore clairement au XVII siècle; c'est-à-dire que les expressions mêmes que l'on trouve dans les sources peuvent nous induire en erreur.

Nous n'entrerons pas ici dans une discussion minutieuse sur les conditions structurelles de l'apprentissage des langues et la perception ou non-perception de sa nécessité dans les manuels de diplomates ${ }^{121}$. Retenons cependant certains principes et certaines réalités fondamentales: les manuels du parfait ambassadeur des

118 En effet, comme le remarque à juste titre RUSSELL, il est extrêmement difficile d'arriver à des conclusions certaines sur ce sujet, ou du moins à des évaluations, car on ne peut trouver qu'accidentellement des éléments à ce propos, se trouvant dans une phrase cachée ou à côté du chemin que le chercheur parcourt: «Evidence on this subject is hard to find and to evaluate; it comes upon one, by accident, in some hidden phrase or aside«, cf. EAD., Diplomats at Work, p. XVI (citation) et p. 3.

119 Pour ne citer qu'un exemple flagrant, cf. le traité d'Osnabrück imprimé en français dans: DumonT, Corps universel, t. VI/1, p. 469-490 (contrairement à certains de ses collègues tels que Frédéric Léonard, Dumont a toutefois le mérite de signaler les éditions précédentes en français, en latin et en allemand).

120 Cf. Louis MORÉRI, Le Grand Dictionnaire, t. III, p. 821; passage cité dans Guido BraUN, Une tour de Babel? Les langues de la négociation et les problèmes de traduction au congrès de la paix de Westphalie (1643-1649), dans: BABEL (dir.), Le diplomate au travail, p. 139172 , ici p. $142-143$, n. 14.

121 Pour la connaissance de l'allemand en France, on se reportera toujours à LÉVY, La langue allemande, ici t. I. 
$\mathrm{XVI}^{\mathrm{e}}$ et XVII ${ }^{\mathrm{e}}$ siècles exigent en général que tout ambassadeur sache parler le latin. Au XVIe siècle, le Vénitien Ottavio Maggi avait revendiqué que l'ambassadeur ne dût "pas seulement savoir écrire et parler le latin avec un raffinement tout classique, mais [qu']il d[û]t aussi être un maître en grec, en espagnol, en français, en allemand et en turc «122. On peut supposer que les négociateurs qui satisfaisaient à cette exigence étaient très rare. Mais ces exigences étaient tout à fait exceptionnelles dans les manuels du parfait ambassadeur. Alberico Gentili souhaitait que l'ambassadeur parlât, outre le latin, trois langues étrangères, dont la langue du pays où il devait être envoyé. Même si les auteurs considéraient donc que tout diplomate devait parler plusieurs langues étrangères, Juan António De Vera recommandait que l'ambassadeur se servît de la langue de son souverain pour lui rendre honneur ${ }^{123}$; selon Mattingly, cette position correspondait parfaitement à l'esprit du XVIIe siècle ${ }^{124}$, où l'on pensait que l'usage de sa propre langue rendait gloire au souverain que l'ambassadeur représentait. De même que les autres auteurs, Rousseau de Chamoy insista, en 1697, sur le caractère indispensable du latin, tout en admettant que sa connaissance ne suffisait pas:

Une autre qualité qui est fort à désirer en un Ambassadeur, c'est la connaissance des langues étrangères. La latine luy est absolument nécéssaire parce qu'on la parle presque partout, et qu'elle peut ainsy suffire en quelque façon, au deffaut des autres, mais comme elle n'est pourtant sçeue que d'un certain nombre de gens, il est souvent réduit à n'avoir commerce qu'avec peu de personnes, s'il ignore les autres langues, et mesme ceux qui entendent la latine ne la possédant pas toujours avec la perfection et la délicatesse que le bien des affaires demande, il est souvent privé des avantages qu'on peut tirer dans les négociations de certains tours d'expression qu'il faut donner aux choses qu'on veut estre entendues d'une certaine manière ${ }^{125}$.

Par ailleurs, Rousseau de Chamoy estimait qu'il était très important de connaître la langue du pays où l'on était accrédité, soit pour obtenir des renseignements des couches de la population ne parlant pas le latin, soit pour se passer d'interprète dans les négociations avec les princes; il explique très précisément les inconvénients qui pouvaient résulter d'un manque de connaissances linguistiques:

On peut encore dire que quand un Ambassadeur ne sçait que le latin, il est de mesme hors d'estat d'avoir commerce avec les femmes et avec la plus grande partie des gens de guerre et des marchands, et l'on ne peut disconvenir qu'il perde en cela beaucoup d'avantages que ces différens commerces peuvent souvent procurer à un homme habile, pénétrant, et qui profite de tout. C'est à quoy la langue du pays, s'il la sçavoit, luy serviroit avantageusement, et l'on

122 Ottavio Maggi, dans son ouvrage »De Legato«, imprimé à Hanau, en 1596, cf. Stephen GASELEE, The Language of Diplomacy. Being the Gregynog lectures, delivered at University College, Abertyswyth, on October 31st, November 1st and November 2nd, 1938, Cambridge 1939 , p. 60.

123 Juan António de Vera publia son traité »El Embajador « à Séville, en 1620.

124 Cf. Garrett MATTINGLY, Renaissance Diplomacy, Londres 1970 (The Bedford historical series, 18), p. 186-187; sur les langues recommandées dans les manuels pour diplomates, voir aussi PICAVET, Le français, p. 582-583; OSTROWER, Language, t. II, p. 732.

125 [Louis RouSSEAU DE CHAMOY], L'idée du parfait ambassadeur, par [...] gentilhomme de la chambre du roi et son ministre auprès de la diète germanique, Paris 1912, ici le chapitre: De la connaissance des langues étrangères, p. 27. 
ne peut ainsy trop souhaiter qu'il l'entendist et qu'il la parlast. Il est vray, à nostre égard, que la pluspart des Princes et des ministres avec lesquels les Ambassadeurs de France ont à traiter parlent françois, mais il s'en trouve aussy un grand nombre qui ne le sçavent point, et c'est une chose pleine d'inconvéniens désavantageux d'estre alors obligé de leur parler par un Interprète. Quelque soin qu'on prenne de luy dire ce qu'on veut qu'il explique, son peu d'habileté personnelle dans les affaires et les tours différens des langues peuvent toujours faire douter avec justice, qu'il n'ait pas dit les choses avec la force ou dans le sens qu'elles soient entendues, et comme c'est pourtant souvent dans ces tours délicats et insinuants autant que dans la chose mesme que consistent l'avantage et les lumières que l'habile négociateur peut tirer de ses audiences et de ses visites, encore une fois on peut assez dire combien il serait avantageux que l'Ambassadeur entendist et parlast luy-mesme la langue de la Cour où il $\operatorname{ser}^{126}$

Au début du XVIII ${ }^{e}$ siècle, François de Callières (1645-1717) insistera encore sur la maîtrise du latin, exigeant aussi celle de trois autres langues étrangères, dont l'allemand:

Chaque sujet qui se destine à être employé dans les négociations pour le service du Roy, doit sçavoir les langues Allemande, Italienne et Espagnolle, avec la latine, qu'il seroit honteux d'ignorer à un homme engagé dans les employs publics, cette langue étant la langue commune de toutes les Nations Chrétiennes ${ }^{127}$.

Outre les connaissances linguistiques proprement dites, n'oublions d'ailleurs pas que le diplomate en tant qu'orator devait aussi être théoriquement capable d'accompagner ses propos de gestes propres à convaincre ou à persuader ses interlocuteurs 128 .

En ce qui concerne le congrès de Westphalie, il est à noter que certains diplomates parlaient très bien plusieurs langues étrangères et que presque tous maîtrisaient plus ou moins bien le latin. L'italien était toujours une langue de prédilection pour les gens cultivés, le français était par contre moins bien connu qu'un siècle plus tard et l'allemand parlé par les ressortissants du Saint-Empire et des puissances nordiques. Les envoyés au congrès étaient naturellement aidés par le personnel de leurs chancelleries et disposaient d'interprètes et de secrétaires étrangers qui nous sont parfois bien connus. Ainsi les deux ambassadeurs suédois, Johan Adler Salvius et Johan Oxenstierna, avaient chacun un secrétaire allemand, respectivement Georg Keller et Heinrich Wulfrath ${ }^{129}$. Longueville avait comme

126 Ibid., p. 23. Genet écrit à propos de ce passage de Rousseau de Chamoy: »Il n'y a presque rien à ajouter à son parfait exposé «, cf. Raoul GENET, Traité de diplomatie et de droit diplomatique, 2 vol., Paris 1931 (publications de la Revue générale de droit international public, 3, 5), ici t. I, p. 121.

127 Cf. [François] DE CALlıÈRES, De la maniere de negocier avec les souverains. De l'utilité des negociations, du choix des ambassadeurs \& des envoyez, \& des qualitez necessaires pour réuissir dans ces emplois [...], Amsterdam 1716; ID., The Art of Diplomacy, éd. par H. M. A. KEENS-SOPER, Karl W. SCHWEIZER, New York 1983, p. 98; dernière édition française: François DE CaLlières, L'Art de négocier en France sous Louis XIV, éd. par Jean-Claude WAQUET, Paris 2005.

128 Apparemment, certains ambassadeurs pouvaient même combler leurs problèmes linguistiques par d'autres qualités rhétoriques, tel Marlborough s'adressant aux Etats-Généraux des Provinces-Unies, cf. PRADIER-FodéRÉ, Cours de droit diplomatique, t. II, p. 316.

$129 \mathrm{Ce}$ dernier fut remplacé par Steiniger, auparavant secrétaire allemand du chancelier Axel 
secrétaire et interprète Jeremias Jacques Stenglin ${ }^{130}$. La délégation catalane, dirigée par Fontanella et dont nous avons une liste des membres ${ }^{131}$, comportait un interprète sur un total de vingt personnes. Quand Henri de La Court fut nommé résident français à Osnabrück, Servien lui donna des conseils pour choisir son personnel et lui écrivit qu'il lui faudrait, entre autres, »un bon secrettaire et quelqu' un encores qui puisse escrire en latin «132. Parfois, les diplomates recouraient aussi aux services de ministres d'autres puissances pour se faire renseigner sur les délibérations auxquelles ils ne participaient pas; ainsi, Servien, en mission à La Haye, obtenait non seulement des renseignements sur les délibérations des ÉtatsGénéraux, mais aussi des traductions françaises des actes de cette assemblée que Joachim de Wicquefort lui remettait ${ }^{133}$. Les documents que les archives des puissances présentes en Westphalie conservent de nos jours, attestent d'un inlassable effort de traductions dans les chancelleries des différentes délégations ${ }^{134}$.

Oxenstierna; Wilhelm KoHL (éd.), Acta Pacis Westphalicae, série II, section C: Die schwedischen Korrespondenzen, vol. 4/1-4/2: 1648-1649, avec le concours de Paul NACHTSHEIM, Münster 1994 (APW II C 4), ici t. 4/1, documents nos 201, 235, 238 (cf. aussi l'index, t. 4/2, p. 1185-1186); sur Keller: Ernst Manfred WERMTER (éd.), APW, série II, section C, vol. 1: 1643-1645, Münster 1965 (APW II C 1), p. 937; Gottfried LoRENZ (éd.), APW, série II, section C, vol. 3: 1646-1647, Münster 1975 (APW II C 3), p. 14, n. 2.

130 BosBaCH, Einleitung, APW II B 3/1, p. XLIV; Julia Gauss (éd.), Johann Rudolf Wettsteins Diarium 1646/47, Berne 1962 (Quellen zur Schweizer Geschichte, nouv. sér., III 8), p. 302-303. Pourtant, l'»Estat du logement« du duc de Longueville (Stockholm, Riksarkivet, Diplomatica Germanica 4 fol. 964), peut-être incomplet, ne fait état d'aucun interprète dans sa suite. L'absence d'interprète dans cette liste pourrait aussi s'expliquer par le fait que Stenglin (comme d'autres interprètes) servait aussi de secrétaire; en général, leur absence dans les listes des délégations ne permet pas de conclure que celles-ci ne disposaient pas d'interprètes. En effet, les chancelleries des délégations et des cours européennes étaient moins spécialisées que les administrations modernes; cf. ROOSEN, Age, p. 44-50.

131 Staatsarchiv Osnabrïck, répertoire 100, section 1, no 116 fol. $297^{\prime}$.

132 Lettre du [7] juillet 1646; KELCH-RADE, TisCHER, APW II B 4, document no 58, p. 176177, ici p. 176. La Court avait (aussi) un secrétaire allemand, cf. sa lettre à Lionne (secrétaire de Mazarin et d'Anne d'Autriche) du 22 octobre 1647, copie: AE, CP All. 97 fol. 449-451, ici fol. 450; pour la France en général, cf. aussi la liste des pensions payées en 1644, entre autres aux interprètes: AE, MD France 289 fol. 157-162'.

133 Joachim de Wicquefort (1596-1670) fut ministre résident de Hesse-Cassel à La Haye de 1645 à 1665 . Pour les informations et les traductions fournies par Wicquefort, voir par exemple: Joachim de Wicquefort à Servien, [La Haye], 15 avril 1647, original: AE, CP Hollande (Holl.) 41 fol. 121. Par ailleurs, les documents que la chancellerie de Servien a produits durant cette mission témoignent aussi d'une intense activité de traduction au sein de celle-ci; $\mathrm{cf}$. les minutes de nombreuses versions françaises de documents néerlandais émanant de cette chancellerie et dont les références sont indiquées dans BRAUN, APW II B 5/1-2, passim. De temps en temps, des notes précisent qu'on est en train de faire des traductions qui seront ensuite envoyées à Paris; cf. par exemple ibid., t. 5/2, p. 871, n.18.

134 Par exemple, dans Archivo General de Simancas, Secretaría de Estado, fasc. 2429, on trouve de nombreuses versions espagnoles de lettres en langues étrangères - par exemple celles qui ont été envoyées par les ambassadeurs de l'empereur - et de propositions, etc., qui datent de 1647, et qui, d'après des notes ajoutées à leur début, ont été traduites du latin, de l'allemand ou bien de l'italien; on peut d'ailleurs noter que les propositions en langue française y sont conservées dans leur teneur originale. 
Les négociateurs disposaient d'ailleurs de très bons instruments de travail; outre les manuels diplomatiques pour leur instruction générale, tel celui de Callières ou celui de De Vera, ils avaient, pour leur formation linguistique proprement dite, depuis la fin du XVIe siècle, un grand nombre de dictionnaires qui comptaient parfois plus de mille pages et étaient souvent accompagnés d'un traité de grammaire. À part les dictionnaires bilingues, on peut en trouver d'autres regroupant de trois à six langues; les dictionnaires français-allemand-latin étaient fréquents. Les méthodes qui étaient récommandées dans ces dictionnaires pour apprendre les langues correspondent essentiellement à celles d'aujourd'hui: c'est ainsi qu'un dictionnaire publié en 1715 recommande, par exemple, de fréquenter des étrangers et de faire des voyages afin de se perfectionner, etc. ${ }^{135}$.

\section{Les langues de la négociation et des traités de Westphalie: remarques générales}

Pour les négociations mêmes, il faut d'abord constater qu'il n'y avait pas de langue unique pour tous les fils des pourparlers, ni même de règle générale pour toutes les parties. Cette diversité tient en partie au mode de travail du congrès, qui ne se réunit jamais en séance plénière. Les États, répartis entre les deux villes de Münster - où siégeaient grosso modo les États catholiques ainsi que les ambassadeurs des Provinces-Unies - et d'Osnabrück - ville des puissances protestantes et d'une partie de la délégation impériale - négociaient soit directement avec leur adversaire, ce qui était le cas à Osnabrück et aussi pour les pourparlers entre les Provinces-Unies et l'Espagne à Münster, soit indirectement, par l'interposition d'un médiateur. La France choisit ce dernier procédé pour ses négociations avec l'empereur et le roi d'Espagne, en se servant de la médiation du nonce apostolique Fabio Chigi et de l'ambassadeur de la république de Venise Alvise Contarini, ainsi que de celle des plénipotentiaires néerlandais à partir du mois de septembre $1646^{136}$. Les états de l'Empire se réunissaient dans les trois collèges traditionnels des électeurs, des princes et des villes, répartis eux aussi entre Münster et Osnabrück, et formaient de plus deux corps en fonction de leur appartenance religieuse, le Corpus catholicorum et le Corpus evangelicorum ${ }^{137}$.

135 Au sujet des dictionnaires français-allemand et des manuels de grammaire de l'époque, cf. BRAUN, Von der politischen zur kulturellen Hegemonie, p. 182, 187-189, 192, 194-195.

136 Cf. Konrad REPGEN, Friedensvermittlung und Friedensvermittler beim Westfalischen Frieden, dans: ID., Dreißigjähriger Krieg und Westfälischer Friede, p. 695-719; sur la médiation néerlandaise, cf. aussi TISCHER, Französische Diplomatie, passim (voir l'index, p. 475). Pour la médiation de Chigi entre les Français et les Espagnols, cf. également BRAUN, Friedensvermittlung.

137 Cf. Fritz WoLfF, Corpus Evangelicorum und Corpus Catholicorum auf dem Westfälischen Friedenskongreß. Die Einfügung der konfessionellen Ständeverbindungen in die Reichsverfassung, Münster 1966 (Schriftenreihe der Vereinigung zur Erforschung der Neueren Geschichte e.V., 2). 
Si le latin était la principale langue des diplomates au congrès, il était loin d'être la seule. Comme langue commune de l'Occident chrétien, dont le SaintEmpire se voulait le défenseur et l'empereur le chef suprême, il fut employé dans les traités de paix entre l'empereur, les états de l'Empire et respectivement la France et la Suède, signés le 24 octobre 1648 à Münster ${ }^{138}$. Par contre, le troisième traité, la paix particulière entre l'Espagne et les Provinces-Unies conclue le 30 janvier 1648 à Münster, est un acte bilingue, dressé en néerlandais et en français ${ }^{139}$.

Réfléchissant à la question de la langue du traité de paix, les Français étaient en effet arrivés à la même conclusion que les Impériaux et les Suédois et, dans une note rédigée probablement par Théodore Godefroy, s'étaient résignés à sa rédaction en latin ${ }^{140}$. La principale objection soulignée par l'auteur est »qu'il y va de l'honneur de la France que le traicté se fasse en langue françoise plustost qu'en une autre langue«. »Mais à cela il se peut respondre, poursuit-il, qu'il n'y aura pas un grand adventage d'honneur si le traicté se faict d'une part en langue françoise et d'autre en langue alemande, selon que vraysemblablement l'Empereur le demandera au réciproque«. Ses principaux arguments en faveur du latin sont au nombre de trois: premièrement, il dit que les traités de paix, de trêve et de confédération entre les principales puissances de l'Europe se faisaient généralement en latin (il s'agit donc d'une coutume bien établie depuis longtemps); deuxièmement, qu'il en était de même pour les traités passés par la France avec les Habsbourg, excepté ceux qui concernaient uniquement la Flandre, l'Artois ou la Bourgogne; troisièmement, il ajoute:

Il est à propos que ce traicté se fasse en langue latine, ainsi qu'il s'est observé au traicté de Ratisbone, en l'an mille six-cent trente, entre l'Empereur Ferdinand II et le feu Roy ${ }^{141}$, pour ce qu'il est nécessaire que les princes qui traictent entre eux, soit de paix, de trefve, ou de confédération et alliance, s'entendent l'un l'autre en ce dont ils conviennent, et qu'il faut éviter, tant que faire se peut, les doubtes qui peuvent naistre sur le sens des mots, si le Roy faict le traicté en françois, et l'Empereur en aleman[d], qui sont langues du tout différentes, et n'ont rien de commun l'une avec l'autre.

Derrière le latin, on voit pourtant s'établir le français comme langue des diplomates, mais il doit encore se partager le palmarès avec d'autres langues vernaculai-

138 Quoique le traité avec la Suède fût daté »à Osnabrück« pour des raisons politiques. Les deux traités sont publiés dans: OschMANN, APW III B $1 / 1$.

139 Il est donc bizarre que ce traité ait été publié en latin, en allemand et en néerlandais sans sa version française, qui (contrairement aux traductions allemande et latine) fait foi: Gerd DETHLEFS (éd.), Der Frieden von Münster 1648. Der Vertragstext mit einem zeitgenössischen Druck und die Beschreibung der Ratifikationsfeiern, avec le concours de Johannes ARNDT et de Ralf KıöTZER, Münster 1998. Autre édition du texte néerlandais: C. SMTT, Het vredesverdrag van Munster. 30. Januari 1648, Leyde 1948, p. 30-60; le texte français dans: Dumont, Corps universel, t. VI/1, p. 429-441. Les Provinces-Unies concluaient ordinairement leurs traités en néerlandais et en français.

140 Intitulée Que le traicté de paix entre l'Empereur et le Roy se doibt plustost faire en langue latine que en [sic] langue françoise«; copie de Nicolas Doulceur, secrétaire de Godefroy: IF, Coll. Godefroy 22 fol. $90-91$ '.

141 Louis XIII. 
res, surtout l'italien, langue des médiateurs Chigi et Contarini et l'une de celles de la cour impériale de Vienne ${ }^{142}$, mais aussi l'allemand, souvent parlé par les Allemands eux-mêmes, bien sûr, mais aussi plus généralement par les puissances du Nord, et, dans une moindre mesure, l'espagnol et le néerlandais.

Seules l'Espagne et les Provinces-Unies suivaient une règle précise dans leurs négociations, établie par l'accord, politiquement très important, du 5 mai $1646^{143}$. En vertu de cette convention, les plénipotentiaires espagnols accordèrent à leurs homologues néerlandais le rang d'ambassadeurs d'une puissance souveraine, ce que les plénipotentiaires français, pourtant alliés des Provinces-Unies, ne surent reconnaître qu'avec des restrictions. Ce fut pour les Néerlandais un premier pas vers leur indépendance et leur souveraineté nationale, finalement reconnues par le roi d'Espagne dans le traité de paix de Münster du 30 janvier 1648, où les Provinces-Unies échappèrent définitivement à la domination espagnole. Le même rang diplomatique accordé à leurs ambassadeurs n'était pas seulement la conditio sine qua non posée par les Hollandais pour entrer dans les négociations substantielles, c'était déjà, de facto, leur reconnaissance sur le plan du droit international. Elle se traduisait au niveau du cérémonial par une parfaite égalité entre les deux délégations, qui devaient par conséquent tenir alternativement leurs séances dans les hôtels des deux ambassades. On convint, en outre, de négocier en latin, en français ou en »néerlandais « ${ }^{144}$; les résultats des négociations devaient être consignés par écrit, et ceci exclusivement en français et en néerlandais. Ces langues étaient en quelque sorte aussi celles des Espagnols (l'un de leurs plénipotentiaires, Antoine Brun, était Franc-Comtois, un autre, Joseph de Bergaigne, Anversois), et le français était en même temps la langue administrative des Pays-Bas espagnols ${ }^{145}$. Re-

142 À l'époque de Léopold Ier, l'italien était non seulement la langue de la cour, mais aussi de la ville de Vienne (où un journal était publié en langue italienne); à la cour, marquée par une »multilingual culture «, l'italien était la langue prédominante; de plus, les artistes italiens (surtout des peintres) y étaient nombreux, et la première biographie officielle de Léopold I ${ }^{e r}$, la »Historia di Leopoldo Cesare « de Galeazzo Gualdo Priorato fut écrite en italien (3 vol., 1670). Cf. Maria Goloubeva, The Glorification of Emperor Leopold I in Image, Spectacle and Text, Mayence 2000 (Veröffentlichungen des Instituts für Europäische Geschichte Mainz, Abteilung für Universalgeschichte, 184), en particulier p. 41, 59-60, 62, 67, 77-79, $149,158,184-185,215,218$; malheureusement, Goloubeva ignore que l'emploi des langues était soumis à des règles, de sorte qu'elle peut constater que certaines langues étaient utilisées mais non pas pour quelles raisons.

143 Copies: AE, CP Munster 1 fol. 21-21'; IF, Coll. Godefroy 87 fol. 396-397; il a été imprimé dans: Lieuwe van AITZEMA, Historia Pacis, Foederatis Belgis ab Anno 1621 ad hoc usque tempus tractatae, Leyde 1654, p. 376.

144 C'est ainsi qu'on traduit généralement l'accord du 5 mai 1646: cf. DickmanN, Der Westfälische Frieden, p. 215; BOSBACH, Einleitung, APW II B 3, p. LXXX. En revanche, TISCHER traduit par "Flämisch«, EAD., Französische Diplomatie, p. 311, n. 73. Les sources disent, on l'a vu, »flamand« au lieu de »néerlandais $«$.

145 La renonciation à l'emploi de l'espagnol fut-elle donc un signe politique que les Espagnols donnèrent aux Néerlandais pour montrer leur disposition à conclure la paix? Michael ROHRSCHNEIDER le pense bien, cf. son compte rendu de Rainer BABEL (dir.), Le diplomate au travail, dans: sehepunkte 5 (2005), no 4: "Le fait que, par exemple, les Espagnols aient accepté le néerlandais et le français comme langues de leurs négociations menées par écrit avec 
noncer à l'emploi de l'espagnol dans la négociation apparaît donc comme un sacrifice modeste de la part des Espagnols, du moins si on le compare aux autres concessions faites en faveur des Néerlandais. Il n'est pourtant pas sans intérêt de noter cette concession linguistique et de les voir renoncer (sans état d'âme?) à l'emploi de l'espagnol puisque Peñaranda, premier plénipotentiaire du Roi Catholique, ne parlait pas bien le français (du moins si l'on en croit ses propres aveux $)^{146}$, de sorte qu'il eût certainement été plus pratique pour lui de pouvoir s'exprimer en espagnol. Le compromis linguistique traduisit en effet la ferme volonté politique des Espagnols d'arriver à un traité de trêve ou de paix avec leur adversaire néerlandais. Les Hollandais se servaient d'ailleurs de la même façon du français et du néerlandais dans leur correspondance avec les plénipotentiaires français ${ }^{147}$.

Pour les autres puissances souveraines et les états de l'Empire, les choses sont bien plus compliquées; afin d'analyser leurs usages linguistiques, il faut opérer une distinction fondamentale, à savoir entre les négociations orales et les documents que les délégations échangeaient entre elles ou déposaient auprès des médiateurs. L'usage oral était flexible et éphémère, l'usage écrit pouvait être péremptoire et définitif; pour celui-ci, des compromis étaient donc plus difficiles à obtenir. La situation à Osnabrück, où se regroupaient les seuls États septentrionaux, est plus facile à comprendre que celle qui existait à Münster, où se côtoyaient les langues méridionales et germaniques.

En ce qui concerne les langues comme instrument des négociations, il faut d'abord considérer les instructions données aux ambassadeurs, puis les langues employées dans les documents et enfin la querelle au sujet des capacités linguistiques requises de la part des diplomates.

\section{Les langues, instrument des négociations de Westphalie}

Les Suédois étaient tenus à un usage certain par leurs instructions. L'article $27 \mathrm{de}$ leur instruction principale du 15 octobre $1641^{148}$ permit aux ambassadeurs de traiter en allemand, en latin, en français ou dans une autre langue, tout en donnant la préférence au latin et en précisant que tous les documents devaient se rédiger ex-

les Néerlandais fut sans aucun doute une concession politique, car l'Espagne avait tout intérêt à conclure rapidement un accord séparé avec les États-Généraux « ("Dass beispielsweise die Spanier das Niederländische und das Französische als schriftliche Verhandlungssprachen in ihren Verhandlungen mit den Niederländern zuließen, war zweifellos eine politische Konzession, denn Spanien war an einer baldigen Seperatverständigung mit den Generalstaaten gelegen () .

146 Nous remercions Konrad Repgen d'avoir bien voulu nous signaler ce fait. Michael Rohrschneider a cependant précisé que ce chef d'ambassade comprenait un peu le français.

147 Ainsi que nous le rapportent d'Avaux et Servien dans une lettre du 3 mars 1645 (adressée à Brienne); BosBACH, APW II B 2, document no 49.

148 APW I 1, document no 17 p. 231-255, art. 27: p. 245, art. [53]: p. 255. 
clusivement en latin. L'article 53 (article non numéroté dans l'original) stipula l'usage de la même langue dans le traité qui serait signé à la fin des négociations.

Le chancelier de Suède, Axel Oxenstierna, confirma cet ordre en écrivant à son fils Johan, ambassadeur suédois à Osnabrück, de veiller à ce que la communication écrite avec les Allemands et les Français se fasse toujours en latin ${ }^{149}$. Toutefois, l'on peut constater que le ministre résident de Suède à Münster, Schering Rosenhane, rédigea en français ses premières lettres adressées au ministre résident de France, Saint-Romain ${ }^{150}$; on sait par ailleurs que Rosenhane, qui devint pendant le congrès de Westphalie ambassadeur de Suède à Paris, parlait bien le français et l'utilisait couramment dans les conférences avec les envoyés français. Or, les deux ambassadeurs suédois, Johan Oxenstierna et Salvius, lui envoyèrent, le 25 septembre 1643, l'ordre absolu de se servir dorénavant du latin dans sa correspondance avec les Français ${ }^{151}$. Rosenhane obéit ${ }^{152}$. Si les Suédois ne le cédaient donc pas aux Français, ils admettaient bien l'allemand dans leur correspondance avec les princes de l'Empire, notamment avec leurs alliés, et en particulier la landgravine de Hesse-Cassel. Le duc de Wurtemberg s'adressait également en allemand aux Suédois, et nous avons une lettre de Johan Oxenstierna aux députés bavarois du 14 octobre 1647 elle aussi rédigée en allemand ${ }^{153}$. Par contre, certains princes de l'Empire tenaient au latin traditionnel dans leurs relations avec les étrangers, tel l'électeur de Brandebourg, grand adversaire des Suédois à cause de leurs prétentions respectives sur la Poméranie ${ }^{154}$, et qui leur adressa, le 10 décembre 1644, une lettre latine ${ }^{155}$. Ils employaient également (et, si l'on en croit leurs lettres publiées dans les »Acta Pacis Westphalicae«, même exclusivement) l'allemand dans leur correspondance avec les Danois, prévus initialement comme médiateurs à Osnabrück ${ }^{156}$.

Les Suédois cultivés sont normalement des gens trilingues; outre leur langue maternelle et l'allemand, ils maîtrisent le latin. Cette langue est aussi admise dans leur correspondance interne; on la retrouve aussi en dehors des documents solen-

149 La première fois en mars 1642: Carl C. GJöRwELL (éd.), Bref ifrån Svea-Rikes Canceller Grefve Axel Oxenstiema till Grefve Johan Oxenstierna [...] 1642-1649, t. I, Stockholm 1810, no 5, ici p. 34; cf. aussi Dickmann, Der Westfälische Frieden, p. 214.

150 Par exemple le 7/17 septembre 1643, WeRMTER, APW II C 1, document $n^{\circ} 25$.

151 Ibid., $\mathrm{n}^{\circ} 30$.

152 Sa première lettre latine à Saint-Romain date du 28 septembre 1643, ibid., no 33.

153 KOHL, APW II C 4/1, document $n^{\circ} 12$.

154 Cf. Peter BaUmGaRT, Kurbrandenburgs Kongreßdiplomatie und ihre Ergebnisse, dans: DuchHARDT (dir.), Der Westfälische Friede, p. 469-484.

155 Extrait: WERMTER, APW II C 1, p. 451.

156 Pour une étude plus détaillée de l'emploi de l'allemand par les Suédois, cf. BrauN, Tour de Babel, p. 149-154, p. 153-154 pour le code utilisé par les Suédois dans la partie de leur correspondance qu'il fallait chiffrer, et qui comprenait d'un côté des chiffres correspondant aux lettres de l'alphabet, de l'autre deux listes de mots et de noms propres en allemand. Au sujet de la médiation danoise, voir Gottfried LORENZ, Die dänische Friedensvermittlung beim Westfälischen Friedenskongreß, dans: REPGEN (dir.), Forschungen und Quellen, p. 98148; Michael BREGNSBO, Denmark and the Westphalian Peace, dans: DuCHHARDT (dir.), Der Westfälische Friede, p. 361-367. 
nels, dans la correspondance administrative ordinaire - parfois, semble-t-il, par maniérisme ${ }^{157}$. L'emploi du latin va d'ailleurs de quelques mots insérés dans un texte suédois, ce qui est fréquent, aux lettres intégrales rédigées dans la langue de Cicéron. Cette diversité linguistique de la correspondance se réflète par ailleurs dans l'organisation actuelle des archives de Stockholm, où il y a une série pour les lettres en suédois et une autre pour les lettres soit en latin soit en allemand ${ }^{158}$.

Par leur caractère polyglotte, certains personnages, comme la reine Christine, Salvius, d'Avaux et Trauttmansdorff, incarnent ainsi le microcosme du monde diplomatique moderne, lui aussi polyglotte; les langues de la diplomatie sont le reflet de la culture de leur époque: l'humanisme est leur apanage.

Malgré cette flexibilité, les ambassadeurs suédois restaient intransigeants envers les Français; ils rédigeaient toutes les lettres qu'ils leur envoyaient en latin. Quand Salvius eut reçu une lettre de la part des ambassadeurs français ${ }^{159}$, le 25 décembre 1643, il s'inquiéta de ce qu'elle était écrite en français 160 . Cinq jours plus tard, son collègue Oxenstierna insista de même sur l'usage du latin dans la correspondance franco-suédoise, soulignant que les arguments justifiant cette prétention ne manquaient pas (toutefois il ne les donne pas), et il argua que, puisqu'il fallait envoyer ces lettres en Suède et que le latin y était mieux connu, leur rédaction en français serait inadmissible 161 . Le 8 mars 1644, Oxenstierna adressa aux ambassadeurs français une lettre, évidemment en latin, pour légitimer la guerre dano-suédoise, et dans laquelle il les pria de lui répondre au plus tôt en latin ${ }^{162}$. Il se justifia par le fait qu'il ne parlait pas assez bien le français, ce qui était d'ailleurs vrai. Le 31 mars 1644, Oxenstierna put constater avec satisfaction que d'Avaux écrivait enfin en latin à Salvius ${ }^{163}$. Or, les Français n'en restèrent pas là. Finalement, ils se mirent à écrire de nouveau en français, tandis que les Suédois n'abandonnèrent pas pour cela le latin. C'est pourquoi, le 12 août 1646, Salvius écrivit à d'Avaux en latin ${ }^{164}$ tandis que celui-ci lui répondit, six jours plus tard, en français ${ }^{165}$. Dans la correspondance avec la reine de Suède, le latin restait cependant d'usage ${ }^{166}$.

157 Cf., par exemple, Wilhelm KoHL (éd.), Acta Pacis Westphalicae, série II, section C: Die schwedischen Korrespondenzen, vol. 2: 1645-1646, Münster 1971 (APW II C 2), no 98; ID., APW II C 4/1, nos 162, 163, 166, 186, 206.

158 Cette répartition se reflétait aussi dans l'organisation des chancelleries de la cour de Suède au XVII ${ }^{e}$ siècle, Palmstierna., Histoire de l'administration.

159 Cette lettre fait défaut, cf. WERMTER, APW II C 1, p. 109, n. 1.

160 Ibid., no 79.

161 Ibid., n $\mathrm{n}^{\circ} 87$.

162 Ibid., no 129.

163 Ibid., $n^{\circ} 147$. Oxenstierna lui-même était pourtant en peine parce qu'il ne comprenait pas la fin d'une lettre que Saint-Romain avait écrite à son collègue Rorté en français le 4 mars et qu'Oxenstierna avait reçue en tant que pièce jointe à une dépêche de Rosenhane, ibid., p. 188. C'est pourquoi, attendant toujours l'arrivée des ambassadeurs français à Minden, il adressa une lettre à Salvius, déjà à Osnabrïck, afin de lui demander des explications au sujet du paragraphe qui lui posait des problèmes de compréhension, ibid., $\mathrm{n}^{\circ} 147$.

164 KoHL, APW II C 2, document no 162.

165 Ibid., no 167. De la même façon, quand les trois ambassadeurs français reçurent une dé- 
Les Suédois, quant à eux, rédigeaient bien évidemment en latin leurs lettres destinées non seulement aux Français, mais aussi aux Impériaux ${ }^{167}$. Normalement, ils recevaient de la même façon leurs lettres des délégations siégeant à Münster en latin ${ }^{168}$. Conscients de l'usage restreint de leur propre langue, les Suédois devaient bien évidemment aussi recourir aux autres langues pour justifier leur politique et influencer l'opinion publique. Quand, au printemps de 1644, ils publièrent un manifeste contre le Danemark, des versions latine et allemande du texte suédois étaient d'emblée prévues pour assurer sa plus grande diffusion ${ }^{169}$. L'envoi de nombreuses pièces latines et allemandes jointes aux dépêches des plénipotentiaires suédois à leurs supérieurs de Stockholm démontrent que ces langues étaient bien connues à la cour de Suède; plus rarement, ils y envoyaient aussi des pièces françaises sans les traduire en suédois ${ }^{170}$, tandis qu'un document espagnol était normalement traduit ou accompagné de sa traduction ${ }^{171}$.

À Münster, la France cherchait à imposer sa langue aux autres nations, mais cette tentative se faisait encore très discrète (contrairement à ce qui arrivera à partir du règne personnel de Louis XIV). C'est ainsi que les plénipotentiaires français s'étonnèrent de ce que l'envoyé de la ville de Strasbourg, Markus Otto, leur adressa la parole en latin bien que, comme ils le lui objectèrent, le français fût connu à Strasbourg; à quoi Otto leur répondit que les Strasbourgeois étaient Allemands et parlaient donc l'allemand, tout en admettant - comme le faisaient tous les états de l'Empire - le latin comme langue mieux connue par les ressortissants

pêche en latin de la part de leurs homologues suédois (ibid., $\mathrm{n}^{\mathbf{0}} 181$ ), ils leur répondirent, le 12 septembre 1646 , en français (ibid., $n^{\circ} 183$ ).

166 Cf., par exemple, la lettre des plénipotentiaires français à la reine, minutée par d'Avaux, KELCH-RADE, TISCHER, APW II B 4, pièce 1 jointe au no 182. C'est une sorte de compromis que l'on retrouvera aussi au niveau des propositions délivrées par écrit dans les négociations entre Français et Impériaux, où les Impériaux usaient du latin, les Français de leur langue maternelle alors que le traité lui-même, document plus officiel et plus solennel que les simples propositions, devait être rédigé en latin.

167 En témoigne leur dépêche du 8 août 1644 aux ambassadeurs impériaux à Osnabrück, Auersperg et Krane; WERMTER, APW II C 1, document $n^{\circ} 201$. Ils suivaient la même règle pour les dépêches destinées aux potentats étrangers, comme, par exemple, pour leur lettre du même jour au prince Georges Rákóczy de Transylvanie, ibid., nº 202.

168 Citons, par exemple, la dépêche de l'envoyé portugais Pereira de Castro du 30 novembre 1648 (KoHL, APW II C 4/2, document no 441) à laquelle les ambassadeurs suédois répondirent, quatre jours plus tard, aussi bien en latin (ibid., $\mathrm{n}^{\circ} 452$ ).

169 Cf. WERMTER, APW II C 1 , document $n^{\circ} 144$.

$170 \mathrm{Cf}$., par exemple, ibid., les pièces $\mathrm{A}$ à $\mathrm{X}$ jointes au $\mathrm{n}^{\circ} 367$.

$171 \mathrm{Cf}$., par exemple, ibid., pièce $[\mathrm{X}]$ jointe au no 337 , p. 611; l'original de cette proposition espagnole (»Respuesta a la proposicion de los señores plenip:rios de Francia por los de España«, Münster 8/18 avril 1644) avait été envoyé à Johan Oxenstierna et Salvius par Rosenhane, ibid., $\mathrm{n}^{\circ} 322$, p. 574 . Par contre, il semble que Johan Oxenstierna ait eu quelque connaissance de l'espagnol, du moins commande-t-il, le 21 septembre 1645, un ouvrage de l'ambassadeur espagnol Saavedra dans sa version espagnole bien qu'il soit accessible, depuis 1640, dans une traduction latine établie par l'auteur lui-même, ibid., document $\mathbf{n}^{\circ} 391$. Parmi les pièces jointes à la correspondance suédoise, on trouve aussi des lettres vénitiennes adressées à la reine en italien, cf., par exemple, KOHL, APW II C 2, p. 26. 
étrangers; d'Avaux, content de cette réponse, répondit également en latin ${ }^{172}$. En général, les Français au congrès devaient encore se résigner à faire accepter l'emploi de leur langue par eux-mêmes dans leurs relations avec les délégations étrangères, sans que l'heure fût déjà propice à leur imposer son usage actif. En effet, dans l'Empire, le français était encore mal connu ${ }^{173}$.

D'Avaux et Servien n'étaient d'ailleurs pas d'accord sur l'utilité ou la nécessité de parler les langues étrangères pour pouvoir assumer des missions diplomatiques. D'une manière plus générale encore, leurs avis divergeaient sur le latin, que Servien parlait, semble-t-il, moins bien que son collègue ${ }^{174}$. D'Avaux reprocha ouvertement à Servien, membre de l'Académie française, de ne pas bien parler le latin. Le différend entre les deux ambassadeurs au sujet des titres à donner au roi de France dans les lettres en latin atteignit un tel point que de toutes les options on choisit celle qui était pour la France la pire, c'est-à-dire de suspendre l'envoi de toutes ces lettres jusqu'à ce que le procès soit tranché par la cour, et de ne nommer point le roi dans celles qui ne pouvaient supporter aucun ajournement ${ }^{175}$. Mais

172 Winfried KATTERFELD, Die Vertretung Straßburgs auf dem Westfälischen Friedenskongreß, Strasbourg 1912, p. 12.

173 Le 9 juillet 1648 , les ordres demandèrent à la dictature de faire dicter en latin ou en allemand un document concernant la Lorraine, puisque tous les députés ne comprenaient pas le français ("nebens dem Französischen original auch eine version in einer sprache, so allen gesandten bekant, also in der Teutschen oder Lateinischen «); procès-verbal de la séance du collège des princes à Osnabrück (»Re- und Correlation«), 29 juin/9 juillet 1648 , document publié dans: Maria-Elisabeth BrunerT (éd.), Acta Pacis Westphalicae, série III, section A: Protokolle, vol. 3/1-3/6: Die Beratungen des Fürstenrates in Osnabrück 1645-1646, Münster 1998-2009 (APW III A 3), t. 6, no 190, p. 239-255, ici l'avis du directoire de Saltzbourg, p. 251-253, citation p. 253.

174 Si Mazarin, dont Servien était la créature, se moquait secrètement, en parlant à Lionne ou à Servien, de la vanité avec laquelle d'Avaux exposait sa connaissance du latin, l'étiquette exigeait de lui qu'il le loue officiellement pour les lettres d'invitation des états de l'Empire au congrès expédiées le 6 avril 1644 et minutées par d'Avaux. Il écrivit donc à celui-ci qu'elles étaient excellentes, comme toutes ses lettres latines, et qu'il les avait lues avec un grand plaisir: IrSIGLER, APW II B 1, document $n^{\circ} 89$. Pour l'humanisme latin du comte d'Avaux, nous avons d'ailleurs un beau témoignage de Guez de Balzac qui lui écrit: »je ne doute point que le commerce que vous avez avec les bons livres, $\&$ particulierement avecques Seneque, ne vous ayt appris l'art de faire du bien aux hommes «; lettre adressée à d'Avaux, alors ambassadeur du roi de France à Venise, le 2 mai 1627, dans: [Guez DE BALZAC], Les premières lettres de Guez de Balzac, 1618-1627. Édition critique précédée d'une introduction par $H$. Bibas et K.-T. ButLer, 2 vol., Paris 1933-1934, ici t. II, p. 105. Notons aussi que Voiture estimait beaucoup les capacités linguistiques et littéraires du comte, qu'il tenait pour extraordinaires étant donné que d'Avaux devait passer sa vie à mener des négociations diplomatiques, et que le jeune comte de Brienne considérait que ses lettres latines étaient aussi pures que celles de Cicéron et ses lettres rédigées en français aussi élégantes que celles de Voiture et de Balzac; cependant, peu de lettres latines du comte nous sont parvenues, de sorte qu'il est pratiquement impossible de vérifier le bien-fondé des éloges de ses contemporains, voir ibid., appendice I: Notices biographiques sur les correspondants de Balzac, ici la notice biographique consacrée à d'Avaux, p. 137-138.

175 Les lettres sur ce sujet sont trop nombreuses pour que nous puissions les citer ici, cf. IRSIGLER, APW II B 1, l'index, p. 917 (titres des rois de France). 
d'Avaux, attaqué par Servien, alla plus loin, et écrivit le 18 août 1644 à la reine régente Anne d'Autriche:

[Monsieur Servien] fait aussy injure à l'université de Paris, et a tant d'aversion de la langue latine qu'il traitte avec mespris ceux qui l'enseignent et ceux qui la sçavent. En cet endroit, Madame, je me sens obligé de vous dire très véritablement qu'elle n'est pourtant pas à mespriser. [Elle a été] emploiée autrefois très utilement pour l'Estat. Et il est hors de doute que sans parler latin ou alleman[d], il est impossible de bien servir en Allemagne ny dans tout le Nort. Il n'y a que le seul monsieur Servien qui s'en puisse passer. Il n'appartient qu'à luy de faire honneur et service à la France dans un païs dont il ne sçait pas la langue, ny n'a aucun usage d'une autre qui y est fort commune, et lequel par son propre aveu il ne cognoist que dans la carte. [...] Ce n'est pas, Madame, que je vueille [sic] faire parade du peu de cognoissance que j'ay des langues estrangères. La response que je fis à monsieur Servien n'en touche aucun mot, et $\mathrm{j}$ 'avoue avec luy que cette faculté n'est pas rare ny excellente. Mais je soustiens contre son avis qu'elle est nécessaire aux ambassadeurs du Roy ${ }^{176}$.

Il ne nous semble pas exclu que le parti du latin pris par d'Avaux ait peut-être contribué à pousser Servien - qui avait depuis le mois de décembre 1643 la direction de la chancellerie de l'ambassade - par une sorte d'antagonisme intrinsèque de la délégation française, à prendre celui du français, dont il considérait probablement l'emploi plus digne du roi. Ainsi la »défense« de la langue française au congrès paraîtrait liée à des inimitiés entre les ambassadeurs de France ${ }^{177}$.

Servien nia effectivement la nécessité de parler allemand; il répondit aux objections du comte d'Avaux: »Si vous voulez que je vous parle franchement, on peut avoir quelque connoissance dans les affaires d'Allemagne sans parler Alleman[d] \& sans y avoir demeuré aussi long-temps que vous «178. Cependant on ne peut pas penser que Servien pouvait se dispenser de l'usage du latin, qu'il savait devoir maîtriser pour les négociations; de sorte qu'il écrivit à Henri de La Court lorsque celui-ci s'apprêtait à prendre ses fonctions de résident à Osnabrück: »Il fauldra que vous vous exerciez un peu en venant dans la langue latine, parce que vous en aurez souvent besoin dans les conférences que vous aurez avec les députez qui sont [à Osnabrück], et pour les affaires vous en sçaurez aultant que moy dans huit jours ${ }^{179}$.

Si La Court rapporte, le $1^{\text {er }}$ décembre $1646^{180}$, qu'il a essayé de parler allemand à un secrétaire à Osnabrück, ce qui semble attester quelques connaissances, il doit

176 Original: AE, CP All. 33 fol. 281-286, citation fol. 284'-285; résumé en allemand: IRSIGLER, APW II B 1, document $n^{\circ} 215$. Pour cette querelle au sujet des capacités requises cf. aussi Anne-Marie ÉNAUX, Les plénipotentiaires français en Westphalie, dans: 1648 - la paix de Westphalie - vers l'Europe moderne, Paris 1998, p. 125-134, ici p. 130.

177 Notons qu'en tout cas ce fut au moment où Servien dirigeait la chancellerie de l'ambassade que le français s'imposa dans les lettres des plénipotentiaires français à leurs homologues suédois (ceux-ci commencèrent en effet fin décembre 1643 à s'en plaindre). Servien minuta personnellement bon nombre d'entre elles. Par contre, d'Avaux s'adressa, le 8 avril, le 30 juin et le 15 juillet 1644, à Oxenstierna en latin, et minuta, à l'automne 1646, une lettre latine à la reine de Suède.

178 Lettre du 6 août 1644, publiée dans: Negociations secretes, t. I, p. 83-107, citation p. 89. 179 Lettre du [7] juillet 1646 (voir ci-dessus), KelCH-RADE, TISCHER, APW II B 4, ici p. 176.

180 Lettre adressée à Servien, original: AE, CP All. 67 fol. 394. 
avouer, le $17^{181}$, ses problèmes de compréhension lors d'un dîner chez Salvius où l'un des personnages présents ne parlait ni le latin ni le français. Contrairement aux allégations de Servien, qui devait soutenir son ami malgré son incompétence ${ }^{182}$, on peut donc avancer que le manque de connaissances d'allemand de $\mathrm{La}$ Court nuisait à la France; du moins fournit-il un argument ou un prétexte aux alliés suédois pour exclure celui-ci des pourparlers, ainsi qu'ils l'avaient fait auparavant avec son prédécesseur La Barde ${ }^{183}$. En effet, si l'on en croit la lettre d'Oxenstierna et de Salvius à Servien du 4 mars $1648^{184}$, l'une des raisons par lesquelles ils justifiaient son exclusion de leurs négociations avec les Impériaux et les états de l'Empire fut que La Court ne maîtrisait pas l'allemand et que si les Suédois devaient en conséquence lui servir d'interprètes, cela pouvait se faire plus facilement après que durant les séances. Même si l'on suppose que ce ne fut qu'un prétexte des Suédois pour masquer leur volonté de ne pas laisser l'allié français voir de trop près l'état de leurs négociations, qui avançaient à l'époque assez vite, il en résulta un tort indéniable pour la délégation française. Si Servien réfuta quatre jours plus tard cet argument linguistique, il admit toutefois que $\mathrm{La}$ Court ne fût informé par les Suédois des propos qu'on aurait tenus qu'une fois la séance terminée ${ }^{185}$; on voit que la présence française ne pouvait donc y être que symbolique, une participation réelle de La Court aux négociations étant du point de vue linguistique exclue.

Les Allemands, quant à eux, tenaient au latin, deuxième langue officielle du Saint-Empire depuis 1519. Le latin s'employait notamment dans les relations de l'Empire et de ses princes et villes avec l'étranger. C'est pourquoi les plénipotentiaires de l'empereur protestèrent lorsque les Français leur soumirent leur première proposition en français ${ }^{186}$. Or, non seulement les Impériaux, mais aussi les états de l'Empire exigeaient l'emploi du latin. En conséquence, d'Avaux et Servien leur adressèrent leurs lettres circulaires du 6 avril et du 4 septembre 1644 en latin ${ }^{187}$; en effet, pour mettre ou maintenir les états de l'Empire dans de bonnes dispositions à leur égard, ils ne pouvaient pas se permettre la même liberté qu'envers les Impériaux et ils devaient craindre (pouvons-nous supposer) qu'une lettre française ne pût les choquer et ainsi les inciter à décliner cette invitation.

L'allemand était la principale langue employée dans la correspondance entre les états de l'Empire, et entre ceux-ci et l'empereur. Mais là encore il y avait des exceptions; c'est ainsi qu'on voit l'évêque d'Osnabrück, Wartenberg, adresser au

181 Lettre adressée au même, original autographe, non signé: AE, CP All. 68 fol. 136-136'.

182 TisCHER, Französische Diplomatie, p. 163-167.

183 Cf. ibid., p. 161-163.

$184 \mathrm{KOHL}$, APW II C 4/1, document no 154.

185 Ibid., $\mathrm{n}^{\circ} 159$.

186 Dickmann, Der Westfälische Frieden, p. 214; cf. aussi PHILIPPE, FoERSTER, APW III C 2/1, p. $452-453$.

187 Lettre du 6 avril en latin et en français dans: Negociations secretes, t. I, p. 247-250; lettre du 4 septembre, également en latin et en français: ibid., p. 289-293. 
premier plénipotentiaire de l'empereur, Trauttmansdorff, une lettre italienne ${ }^{188}$, et ce dernier lui répondre en latin ${ }^{189}$. Le latin, tout comme chez les Suédois, est aussi parfois utilisé dans la correspondance entre la cour impériale de Vienne et les ambassadeurs impériaux au congrès ${ }^{190}$. Cette langue était aussi utilisée dans les expertises internes des conseillers juridiques de l'empereur ${ }^{191}$, et dans la correspondance entre les ambassadeurs impériaux à Münster et l'agent à Rome, qui leur répondait en italien ${ }^{192}$.

Outre le latin, l'Empire connaissait aussi l'emploi de l'italien dans ses relations avec l'étranger; cette langue se trouve par exemple employée dans la correspondance du duc Nicolas François de Lorraine avec Trauttmansdorff ${ }^{193}$, ou dans celle du duc de Bavière avec le nonce Bagni à Paris ${ }^{194}$; pour autant, si l'italien est d'usage, ce n'est pas une langue officielle de l'Empire, de sorte qu'il est logique que l'empereur lui-même réponde en latin au duc Nicolas François ${ }^{195}$.

Les textes qui devaient servir de base à la négociation - c'est-à-dire les documents dans lesquels les délégations résumaient leurs prétentions, répondaient à celles de leurs parties ou convenaient des articles à insérer dans le traité de paix étaient normalement (mais pas toujours) rédigés en latin par les Impériaux et les Suédois, et dans leur langue maternelle par les Français. Les Espagnols usaient de l'espagnol envers ces derniers ${ }^{196}$.

188 Publiée dans: Karsten RuPPERT (éd.), Acta Pacis Westphalicae, série II, section A: Die kaiserlichen Korrespondenzen, vol. 3: 1645-1646, Münster 1985 (APW II A 3), p. 453.

189 Publiée ibid., p. 453-454.

190 Par exemple, le vice-chancelier de l'Empire, Kurz, écrivit le 23 octobre 1646 une lettre en latin à Trauttmansdorff, Antje OschmanN (éd.), Acta Pacis Westphalicae, série II, section A: Die kaiserlichen Korrespondenzen, vol. 5: 1646-1647, Münster 1993 (APW II A 5), $\mathrm{n}^{\circ} 85$.

191 Cf., par exemple, ibid., pièce [1] jointe au no 138. Outre le latin, les Impériaux semaient parfois des mots italiens dans leurs lettres. Notons par exemple que, le 4 janvier 1647, Trauttmansdorff informa l'empereur de l'état de la négociation au sujet de Porto Longone, dont Français et Espagnols se disputaient la possession, en lui écrivant: »per il porto di Longone siamo longhi dal porto (»pour Porto Longone, nous sommes loin du port«), ibid., $\mathbf{n}^{\circ} 195$. C'est une des »fleurettes italiennes « qui, d'après Moser, ornaient la langue des Impériaux au congrès de Westphalie, cf. Moser, Staatssprachen, p. 18.

192 Cf., par exemple, les lettres adressées par Nassau et Volmar à Savelli, Münster, 11 et 18 mai 1645, qui sont en latin; Savelli à Nassau et Volmar, Rome, 22 et 29 avril 1645, en italien (cf. FoERSTER, OSCHMANN, APW III C 2/3, p. 68R; ibid., dans l'index chronologique, on trouvera d'autres exemples).

193 RUPPERT, APW II A 3, p. 221-222.

194 BOSBACH, APW II B 2, p. 650-651.

195 RUPPERT, APW II A 3, p. 404-405.

196 Pour les actes bilingues délivrés par les Espagnols aux Français voir ci-dessous. Dans les négociations entre l'Espagne et les Provinces-Unies, comme nous l'avons vu, on utilisa le français et le néerlandais; c'est pour cette raison que les articles provisionnels signés par les Espagnols et par sept des huit ambassadeurs hollandais le 8 janvier 1647 furent rédigés dans l'une et l'autre langue; description des originaux: lettre adressée par Longueville et d'Avaux à Servien, 10 janvier 1647 (BRAUN, APW II B 5/1, no 49, p. $244-249$, ici p. 246); texte français des articles: DumONT, Corps universel, t. VI/1, p. 360-365. Il en va de même pour le traité particulier du 30 janvier 1648; voir ci-dessus. 
Or, souvent les documents n'étaient pas préparés par les délégations ni remis aux médiateurs ou à leurs parties, mais il s'agissait de notes prises au cours des conférences, en général par les médiateurs. Dans les papiers de Chigi, de Contarini et des grandes puissances, l'on trouve par conséquent un grand nombre de documents qui fixent le résultat d'une négociation; les notes que les médiateurs ont prises sont en règle générale en italien, langue qui devient ainsi, par les médiateurs, l'une des principales du congrès, car c'est dans celle-ci qu'ils résumaient les propositions, soumises, le cas échéant, en français ou en espagnol ${ }^{197}$, et souvent le texte italien était ensuite traduit en latin ${ }^{198}$.

Pour ce qui est des langues utilisées dans les conférences, il faut noter que, contrairement à ce qui concerne l'usage écrit, il est assez difficile de saisir leur emploi dans les négociations orales; cette tâche se heurte à de nombreux obstacles: d'abord nos sources ne parlent qu'exceptionnellement des langues employées au congrès - rares sont les témoignages directs, qui se trouvent surtout au début du congrès; c'est ainsi que les Impériaux soulignent, le 24 mars 1644, l'emploi du français dans une conférence avec d'Avaux, qui avait eu lieu le $21^{199}$, et celui du latin par Chigi le lendemain 200 . Parfois, les titres accordés par les diplomates à leurs interlocuteurs peuvent nous renseigner sur les langues qu'ils employaient ${ }^{201}$. Par ailleurs, certains personnages ou délégations sont plus enclins à rapporter l'usage des langues, les Suédois plus que les Français ou les Impériaux, délégation dans laquelle le journal de Volmar, source excellente, représente pourtant une notable exception. Ensuite, quand les correspondants citent les discours de leurs

197 Chigi avouait qu'il écoutait ses interlocuteurs en français ou en espagnol, tout en leur répondant en italien, cf. Guido BRAUN, »La doctrine classique de la diplomatie française «? Zur rechtlichen Legitimation der Verhandlungssprachen durch die französischen Delegationen in Münster, Nimwegen, Frankfurt und Rijswijk (1644-1697), à paraître dans: Christoph KAMPMANN, Maximilian LANZINNER, Guido BRAUN et al. (dir.), »L'art de la paix «. Kongresswesen und Friedensstiftung im Zeitalter des Westfälischen Friedens, Münster [2010] (Schriftenreihe der Vereinigung zur Erforschung der Neueren Geschichte e.V.).

198 Pour citer un exemple qui démontre que ce procédé affecte également le traité de la Suède, signalons les notes de Contarini du 30 novembre 1646 sur l'accommodement entre Salvius et les plénipotentiaires français au sujet de la récompense à accorder au Brandebourg pour la cession de la Poméranie, copie, en italien: Paris, bibliothèque de l'Assemblée nationale (Ass. nat.), ms. 276 fol. 389. On pourrait également citer les articles provisoirement adoptés, le 13 septembre 1646, par les Impériaux et les Français au sujet du dédommagement de la France, cf. Konrad REPGEN, Die kaiserlich-französischen Satisfaktionsartikel vom 13. September 1646 - ein befristetes Agreement, dans: DuchHARDT (dir.), Der Westfälische Friede, p. 175-216, avec l'édition du texte latin conservé par Chigi, p. 204-213.

199 Wilhelm Engels (éd.), Acta Pacis Westphalicae, série II, section A: Die kaiserlichen Korrespondenzen, vol. 1: 1643-1644, avec le concours d'Elfriede MerLA, Münster 1969 (APW II A 1), no 206, p. 313-319, ici p. 315.

200 Ibid., p. 317.

201 Par exemple, les titres que Servien et Wartenberg se donnaient respectivement en différentes langues: cf. Helmut LaHRKAMP (éd.), Acta Pacis Westphalicae, série III, section D: Varia, vol. 1: Stadtmünsterische Akten und Vermischtes, Münster 1964 (APW III D 1), p. 324-325. 
interlocuteurs, ils les traduisent souvent, et la traduction est notamment attestée dans les lettres des Français 202.

Le même problème ressurgit, dans toute son acuité, dans les procès-verbaux des collèges où s'assemblaient les états de l'Empire. En effet, comme Maria-Elisabeth Brunert a pu le montrer pour le collège des princes à Osnabrück ${ }^{203}$, les no-

202 Heureusement, nous avons un témoignage qui atteste cette particularité: en effet, le 3 mars 1645 , d'Avaux et Servien rapportèrent à Brienne des propos adressés de vive voix par Salvius à l'agent impérial Peschwitz, BOSBACH, APW II B 2, document $n^{\circ} 49$. Il découle cependant de la suite de leur lettre que ces propos furent tenus en allemand. Dans la lettre adressée par Longueville, d'Avaux et Servien à Brienne le 12 août 1645 (ibid., $n^{\circ} 185$ ), on trouve pourtant une exception à cette règle: si Contarini y est toujours cité en français, ses derniers mots dans la conférence, très idiomatiques et donc très difficiles à traduire, y sont rapportés en italien. De même dans une lettre du comte d'Avaux et de Servien à Brienne en date du 20 juin 1645 (ibid., $\mathrm{n}^{\circ} 143$ ): Contarini y est cité en latin; les plénipotentiaires français soulignent, de plus, qu'il s'est exprimé dans cette langue et qu'il a répété ladite phrase à deux reprises. Quand une phrase, comme ce fut le cas ici, n'avait pas un sens tout à fait clair, difficile à rendre en français, ou quand il s'agissait de la clause d'une proposition ou d'une stipulation d'un traité (où »le mot est sacramental«, comme dit - on a déjà eu l'occasion de l'évoquer - au XVIII siècle, Charles François Lefèvre de La Maillardière), on pouvait en effet l'insérer telle quelle dans la correspondance française, à condition qu'elle fût rédigée dans une langue connue en France comme le latin, l'italien et l'espagnol. Si l'italien (qui se place derrière le latin) est assez fréquent (on peut par exemple noter les citations des propos de Chigi dans la lettre du comte d'Avaux à Brienne du 24 novembre 1644, IRSIGLER, APW II B l, n ${ }^{\circ} 297$ ), l'allemand ne fait pas partie de ces langues-là; c'est pourquoi les pièces allemandes jointes aux dépêches sont normalement traduites en français. Il y a donc un effort constant et régulier de traduction dans les chancelleries de l'ambassade française au congrès. Citons à ce propos la réponse des députés des princes et des villes présents à Osnabrück en date du 29 juin 1645 à la proposition de Volmar au sujet du mode de travail à adopter pour leurs délibérations, qui fut envoyée à Paris le 8 juillet, BOSBACH, APW II B 2, pièce jointe au $\mathrm{n}^{\circ} 160$ (traduction latine). À cela s'ajoute le problème des citations dans les conférences qui nous sont rapportées dans les dépêches ou dans les procès-verbaux. On citait par exemple, dans les négociations, des proverbes (juridiques) et des auteurs étrangers ainsi que des documents dans leur langue originale, sans qu'il soit toujours à première vue évident qu'il s'agisse d'une citation. Le congrès, paraît-il, sert aussi à propager les proverbes et les expressions idiomatiques; c'est pourquoi Lamberg, dans une lettre à son collègue Trauttmansdorff du 8 octobre 1646 (OschmanN, APW II A 5, n 56), suppose que Salvius ait tiré des Français l'expression »un beau rien entre deux plats«. En revanche, l'emploi d'une expression idiomatique peut être hautement significatif de l'utilisation d'une certaine langue. Quand, le 23 novembre 1646, Oxenstierna, qui parlait l'allemand avec une très grande facilité, dit aux Impériaux qu'il avait assez franchement expliqué sa position la veille sur la cession de la Poméranie aux Brandebourgeois, il se servit de la formule »Teütsch gnug zu verstehen geben « (cf. le procès-verbal de la conférence dressé par les Impériaux, ibid., pièce [1] jointe au $n^{\circ}$ 134); si l'on veut traduire littéralement: »J'ai assez fait comprendre l'allemand aux Brandebourgeois«. Ceux-ci ne voulaient apparemment pas rester en demeure puisque leur envoyé Löben souligna, six semaines plus tard, l'intransigeance de son maître en recourant à la même expression, ibid., $\mathrm{n}^{\circ} 194$. Il va sans dire que la correspondance des diplomates comporte, plus ou moins fréquemment selon leur nationalité, les formules ou concepts latins du droit international qu'ils trouvaient maintes fois dans les traités et dans les ouvrages de droit, et qui constituaient en quelque sorte leur pain quotidien. Toutefois, ces expressions ne représentent qu'un indice d'une valeur limitée pour évaluer le degré de latinité des négociations. 203 BRUNERT, APW III A 3/1, introduction, p. LVI-CXL, en particulier p. CXXVIII-CXXIX et p. CXXXVIII. 
tes prises par les secrétaires durant les séances comportent plus de mots latins que les procès-verbaux mis au net, et les procès-verbaux de plusieurs délégations portant sur la même séance divergent dans l'emploi du latin et de l'allemand; apparemment, les comtes de Vétéravie et le directoire de Magdebourg utilisent plus fréquemment le latin que les autres délégations. Brunert constate qu'il est pratiquement impossible d'établir si, ou dans quelle mesure le latin fut employé dans ces séances. Elle apporte des preuves concluantes pour son hypothèse selon laquelle certaines parties des discours, probablement tenus en allemand, auraient été notées en latin à cause de la brièveté de cette langue par rapport à l'allemand. Cependant, des doutes sur l'usage oral de ces deux langues subsistent.

Malgré ces difficultés, et en prenant quelques précautions, on peut néanmoins dresser le constat suivant: à Osnabrück, on parlait en général un allemand parsemé de latin tandis qu'à Miinster nous trouvons, à côté du latin, surtout le français - pourtant moins répandu qu'au milieu du siècle suivant - et l'italien. Nous y retrouvons d'ailleurs le latin non seulement dans les conférences, mais aussi dans les rues 204 .

Le discours direct employé dans les correspondances nous montre qu'à Osnabrück les Suédois Salvius et Oxenstierna parlaient allemand au député brandebourgeois Löben ${ }^{205}$ tandis que le Français La Court parlait latin avec les Impériaux Lamberg et Krane ${ }^{206}$, ou encore qu'à Münster Théodore Godefroy s'exprimait également en latin ${ }^{207}$. Nous avons aussi des témoignages qui attestent l'emploi du latin par un député néerlandais parlant à l'ambassadeur impérial Nassau208 ou de la langue italienne par le comte d'Avaux envers les députés brandebourgeois, les médiateurs Chigi et Contarini ou encore l'évêque d'Osnabrück, Wartenberg $^{209}$.

Dans les conférences, il semble fréquent que les interlocuteurs s'expriment dans des langues différentes. Ainsi, Nassau s'adresse en français à Wartenberg, qui répond, ainsi que nous le rapporte le Suédois Rosenhane ${ }^{210}$, en italien. Le Vénitien Contarini s'exprime en italien quand il reçoit Rosenhane tandis que celui-ci

204 Johan Oxenstierna, par exemple, rapporta le 27 avril 1648 à sa reine l'assaut que les Espagnols avaient donné au domicile des Portugais, non reconnus par eux comme ambassadeurs, KoHL, APW II C 4/1, document $n^{\circ} 223$. Il nota en latin les injures qui avaient précédé cet acte de violence, que les Espagnols avaient criées en passant devant l'ambassade portugaise, ainsi que la réponse des Portugais.

205 OSChMANN, APW II A 5, documents ${ }^{\text {os }} 158,194$.

206 Ibid.

207 Ibid., $\mathbf{n}^{\mathrm{O}} 189$.

208 Procès-verbal de Nassau, 24 janvier 1647, ibid., pièce [1] jointe au $n^{\circ} 227$.

209 Procès-verbal de la conférence entre le Brandebourgeois Fromhold et les Impériaux, 6 février 1647, ibid., pièce 2 jointe au no 245 ; cf. aussi AE, CP All. 73 fol. 362'-364', "notes« anonymes concernant le cérémonial: »Monsieur d'Avaux parlant d'ordinaire italien avec l'évesque d'Osnabruc, le traite quelquefois de Monsignor [...] Monsieur d'Avaux parle italien avec le nonce, Venise et Osnabruc«.

210 Le 2 décembre 1644, WERMTER, APW II C 1, nº 253. 
lui répond en latin, ainsi qu'il le mande le 24 mai 1644 aux ambassadeurs Oxenstierna et Salvius 211 .

Rosenhane, qui souligne que Contarini et lui se sont exprimés dans leurs langues respectives durant toute la conférence, est d'ailleurs une excellente source pour l'emploi des langues au congrès parce qu'il en rend compte dans sa correspondance et qu'il cite souvent les discours de ses interlocuteurs dans leur teneur originale 212 . Nous savons que Rosenhane parlait régulièrement français avec l'ambassadeur français Abel Servien, puisque, par exemple, il cite les propos de ce dernier en français quand il rend compte de sa visite dans une lettre du 4 juin 1644 , destinée elle aussi à Oxenstierna et Salvius ${ }^{213}$. Par contre, lorsque Salvius était à Münster pour traiter avec ses homologues français, les fréquentes citations latines qu'il employa dans son rapport à Oxenstierna en date du 29 juin $1644^{214}$ nous incitent à penser que ces conférences se tenaient surtout en latin. Dans ce contexte, il convient de noter que Salvius, qui était plus conscient du rôle politique des langues et moins propice aux concessions dans ce domaine, avait, en tant que ministre plénipotentiaire et ambassadeur, un rang bien plus éminent que Rosenhane et que ses visites gardaient par conséquent un caractère plus solennel que celles d'un simple ministre résident; en effet, un ambassadeur incarne, au niveau du cérémonial, le souverain qu'il représente, et ne peut donc pas faire les mêmes concessions qu'un résident, qui occupe une charge subalterne.

La plus grande flexibilité de l'usage oral des langues se manifeste aussi quand Trauttmansdorff instruit, le 21 septembre $1646^{215}$, ses collègues Lamberg et Krane au sujet des titres à accorder au duc de Longueville, respectivement en latin et en français. Il n'avait donc rien contre l'emploi du français dans les conférences. Néanmoins, les procès-verbaux des pourparlers entre les ambassadeurs impériaux et français des 26 et 27 septembre $1646^{216}$ comportent plusieurs citations des discours du comte d'Avaux en latin, de sorte qu'il est à supposer que c'était la principale langue de la conversation. Pourtant, le français fut effectivement employé dans la négociation entre Français et Impériaux, et plus particulièrement par le comte de Nassau ${ }^{217}$. Cet usage est attesté aussi bien par le journal de

211 Ibid., no 159.

212 Cf. BRAUN, Tour de Babel, p. 161 avec plusieurs exemples.

213 WERMTER, APW II C 1, document $n^{\circ} 165$. Ses rapports suivants, en date des 10 et 14 juin 1644 (ibid., nos 174,179 ), montrent que cette conférence ne fut pas exceptionnelle du point de vue linguistique et que, dans ces entrevues avec Servien, on recourait habituellement au français comme langue de conversation. Il ressort d'ailleurs de certaines lettres postérieures que le même usage fut observé dans ses entrevues avec les autres ministres français à Münster, et que non seulement les Français, mais aussi Rosenhane lui-même parlaient français dans ces occasions; on trouve par exemple la citation de sa réponse française au baron de Rorté, dans sa lettre à Johan Oxenstierna du 21 juillet 1644, ibid., nº 193.

214 Ibid., $\mathrm{n}^{\circ} 186$.

215 OSCHMANN, APW II A 5, document $n^{\circ} 13$.

216 Ibid., pièce 2 jointe au no 28.

217 Johann Ludwig, comte de Nassau-Hadamar passait pour un expert des affaires françaises dans la délégation impériale, cf. l'article »Nassau-Hadamar, Johann Ludwig, Count of «, dans: CROXTON, TisCHER, The Peace of Westphalia, p. 203-204, ici p. 203. 
Volmar ${ }^{218}$, collègue de Nassau, que par la correspondance des plénipotentiaires français.

Nous retrouvons d'ailleurs chez les Impériaux les mêmes différences, quoique moins aiguës, que chez les Français. En effet, si Nassau admet le français, qu'il parle bien, Volmar insiste sur le latin et l'italien. Voici le rapport de leur première conférence avec les Impériaux, que Longueville, d'Avaux et Servien envoyèrent à Brienne le 28 octobre 1645:

Nous remismes il y a huict jours à vous mander par cet ordinaire ce qui s'est passé en la visite que les plénipotentiaires de l'Empereur nous ont faicte. [...] La première chose qu'ils firent fut d'envoier demander l'audience par deux gentilshommes avec le titre d'Altesse au premier de nous, et estans venus le lendemain après que le comte de Nassau eut faict son compliment en françois sans user d'aucun titre, son collègue [Volmar] prit la parole ainsy qu'il a accoustumé et dans une longue harangue latine, suivie d'un discours italien donna tousjours le titre d'Altesse et d'Excellence selon qu'il adressa sa parole. Il est à remarquer qu'il parla par ordre de l'Empereur au nom du comte de Nassau et au sien, et qu'outre qu'il est en pareille autorité que ledict comte tous les ministres de l'assemblée luy donnent la main [droite] et le titre d'Excellence et luy font les mesmes honneurs qu'à son collègue. Nous rendismes la visite aux Impériaux quatre jours après où les mesmes choses furent observées ${ }^{219}$.

Les conférences avec les Impériaux étaient donc marquées par un mélange de plusieurs langues; ceci est d'ailleurs valable pour leurs entrevues non seulement avec les Français, mais aussi avec les Espagnols. C'est ainsi que Volmar nota dans son journal, le 8 novembre 1643, la description d'une visite >polyglotte< chez les Espagnols; l'allemand parsemé de latin et d'italien qu'écrit Volmar la rend pratiquement intraduisible 220 .

218 Cf. Moser, Staatssprachen, p. 49-52 (extraits du journal de Volmar, édition de Cortrejus). Volmar écrivait son journal en partie en allemand, en partie en latin. En général, il mélangeait les deux langues, tout en privilégiant l'allemand. Mais parfois, des journées entières sont référées en latin, par exemple: 14 mai 1645, dans: PHILIPPE, FoERSTER, APW III C 2/1, p. 347-349. Quelquefois, Volmar ne se limitait pas au latin et à l'allemand: ibid., p. 345-346, 10 mai 1645 , on trouve une citation d'un document français insérée dans le texte latin du journal (en particulier, p. 346) et une citation en italien de ce qu'avait dit Contarini pendant la conférence (ibid.).

219 BosBaCH, APW II B 2, document n' 247, citation p. 794.

220 Nous la citons donc dans sa teneur originale pour lui laisser toute sa saveur: »Sontags, den 8., haben wir sambtlich don Diego Savedra visitirt. Der hatt un $\beta$ durch zween seiner ministrorum zu eingang des hoffs empfangen und biß zum untern saal vorgehen lassen, allda er und conte Zapata un $\beta$ empfangen und hinauff beglaittet. Die visita bestundt in meris salutationibus, so herr graf Französisch that, ich mit wenigem Italianisch secondirte, darauff seind di discursi in Italiano et Franceso [Francese] durcheinander gangen $\ll$, PHILIPPE, FoERSTER, APW III C $2 / 1$, p. 19. Ces descriptions pittoresques et vivaces font du journal de Volmar la meilleure source de l'emploi des langues, du moins à Münster; si nous l'avons peu citée, c'est parce qu'il faut la lire dans sa version originale. 


\section{Les langues, objet des négociations de Westphalie}

Or, la langue ne fut pas seulement l'instrument, mais aussi l'un des objets des négociations en Westphalie. Dans certains cas, les différends se réglèrent vite. Nous avons vu que les Suédois étaient tenus, par leurs instructions, à veiller à l'usage du latin dans tous les documents. Pourtant, la première proposition qu'ils reçurent de la part des Impériaux, le 4 décembre 1644, était dressée en allemand ${ }^{221}$. Ils prièrent par conséquent les Impériaux de leur soumettre dorénavant leurs propositions en latin, comme cela se faisait à Münster, et ils l'emportèrent peut-être grâce à leur argument de poids: ce fut la menace de répondre en suédois au cas où les Impériaux auraient encore une fois l'audace d'utiliser l'allemand ${ }^{222}$. Si le 21 décembre Lamberg et Krane refusèrent cependant de renoncer totalement à l'allemand, et exigèrent de pouvoir continuer à se servir dans la négociation également du latin et de l'allemand selon ce qui paraîtrait plus pratique et plus utile, le problème des langues ne se posa plus, de facto, d'une manière aiguë entre les Suédois et les Impériaux 223 .

Mais les négociations au sujet des langues pouvaient aussi se régler moins rapidement, ou même jamais, et on les retrouve tout au long du congrès. Le 22 novembre 1646, par exemple (en plein congrès), Oxenstierna écrivit à Salvius qu'il avait refusé le plein pouvoir brandebourgeois pour traiter de la Poméranie parce que, entre autres raisons, il n'était pas en latin ${ }^{224}$; et ce ne fut que six jours avant la signature du traité de Münster que Servien se chargea de faire publier sa ratification par le roi de France en latin 225 .

Si nous avons considéré la rapidité avec laquelle les Espagnols et les Néerlandais étaient parvenus à un accord sur les langues admises dans leur négociation, ce rapprochement préfigurait, ainsi qu'on a pu le constater par la suite, la diligence dans la négociation sur les points essentiels du traité, qui devait mener à la signature de ses articles (bien que provisoires) sept mois plus tard. Les 15 et 16 mai 1648, les Espagnols et les Néerlandais purent enfin ratifier, jurer et publier leur traité particulier; à cette occasion, très solennelle et officielle, on utilisa le latin, le français, l'espagnol et le néerlandais ${ }^{226}$.

${ }^{221}$ Cf. Wilhelm Engels (éd.), Acta Pacis Westphalicae, série II, section A: Die kaiserlichen Korrespondenzen, vol. 2: 1644-1645, avec une annexe de Karsten RUPPERT, Münster 1976 (APW II A 2), p. 113 (références).

222 Cf. le procès-verbal des Impériaux du 21 décembre 1644 (publié ibid., pièce [1] jointe au $\mathrm{n}^{\mathrm{0}}$ 61, ici p. 112) et la lettre adressée par Johan Oxenstierna et Salvius à la reine Christine le 30 décembre 1644 (WERMTER, APW II C 1, document $n^{\circ} 264$ ).

223 Moser n'a donc pas raison de reprocher aux Suédois, et particulièrement à la reine Christine, leur intransigeance au sujet des langues, cf. MOSER, Staatssprachen, p. 23.

224 LORENZ, APW II C 3, document $n^{\circ} 34$.

225 PHILIPPE, FoERSTER, APW III C 2/2, p. 1154.

226 Pour cet événement, voir DiCKMANN, Der Westfälische Frieden, p. 468-470. Un rapport italien, qui a été imprimé en 1648 à Milan et à Rome, confirme l'utilisation des quatre langues mentionnées et prouve que le public italien prêtait une attention particulière au problème des langues; selon ce rapport, l'ambassadeur espagnol Brun tint un discours sur la 
Contrairement aux Néerlandais, les Français ne parvinrent jamais à un accord linguistique formel avec l'Espagne. Ils soumettaient leurs propositions en français et en recevaient les réponses en espagnol. Quand, après la signature des articles provisionnels entre l'Espagne et les Provinces-Unies, les négociations franco-espagnoles entrèrent dans une grave crise qui ne devait jamais être complètement surmontée jusqu'à leur échec définitif en $1648^{227}$, les Espagnols allèrent jusqu'à faire vibrer la corde de la question de la langue dans laquelle le traité serait rédigé. Le 12 février 1647, Longueville rendit compte, dans une lettre qui s'adressait probablement au comte d'Avaux, d'une conférence avec les médiateurs hollandais qui lui avaient transmis la demande de Peñaranda d'accepter les articles de son projet en espagnol, et d'acquiescer à la rédaction bilingue du traité, en espagnol et en français ${ }^{228}$. Bien que cette demande semble mesurée, Longueville la refusa en alléguant l'exemple des traités précédents qui s'étaient faits seulement en français, et en soulignant que les Espagnols les avaient fait de même imprimer, à Anvers $^{229}$, uniquement en français. Les Espagnols répliquèrent que ce n'était vrai que pour le traité de Vervins ${ }^{230}$ et que celui-ci avait été négocié non pas par le roi d'Espagne, mais par procuration par l'archiduc Albert, gouverneur général des Pays-Bas. Le 15 mars 1647, Brienne envoya enfin l'ordre au duc de Longueville d'agréer la rédaction d'un traité bilingue, en français et en espagnol, fondée sur la

paix conclue avec les Provinces-Unies, après le collationnement des instruments de ratification, le 15 mai, lors d'une cérémonie organisée au Friedenssaal (salle de la paix) de Münster: les ambassadeurs espagnols et néerlandais "passaron' in publico ad vn Salone [...] il Sig. Brun recitò vna oratione latina con molta eleganza, nella quale trattò delle conuenienze, e del beneficio, che risultaua da questa gran Pace«. Puis, la version française du traité de paix passé entre l'Espagne et les Provinces-Unies, le 30 janvier 1648, fut lue publiquement à haute voix: "Si lessero susseguentemente con alta voce in lingua Francese li Capitoli della Pace, che fù già stipulata, ed aggiustata a 30 . Gennaro del presente anno $1648 \ll$. Toujours selon ce rapport, le 16 mai, les envoyés espagnols et néerlandais se réunirent de nouveau à l'hôtel de ville de Münster; le traité de paix fut, cette fois-ci, lu en hollandais, devant le public, en présence des ambassadeurs, et sa ratification par Philippe IV en espagnol: »Sendosi giuntati nella detta Casa [della Città] tutti gli SS. Ambasciatori alla loro presenza, \& à vista di tutta la gente si lesse la seconda volta la Capitulatione della stessa Pace in lingua Fiaminga, \& la ratificatione di S.M. in Spagnuolo, e publicossi la Pace ad alta voce«, cf. Relatione di quanto è successo nella ratificatione, e publicatione della pace trà Sva Maestà Cattolica, e gli Stati d'Olanda, fattasi nella città di Munster in Vestfalia sotto li 15. 16. e 17. di maggio 1648. In Milano, e ristampata in Roma, per Lodovico Grignani, 1648 (BNF, Collection Dupuy 721 fol. 278-281').

227 Pour les négociations franco-espagnoles en Westphalie cf. TISCHER, Französische Diplomatie, p. 321-410. Tischer souligne, entre autres, les différences considérables qu'il y a entre les versions françaises et espagnoles des documents échangés entre les deux délégations par l'intermédiaire des médiateurs hollandais.

228 BRAUN, APW II B 5/1, document $n^{\circ} 119$.

229 Il s'agit très certainement de Jean-Jacques CHIFFLET, Recueil des traittez de paix, trêves et neutralité entre les couronnes d'Espagne et de France, Anvers 1643.

230 Le traité de Vervins a été publié plusieurs fois, par exemple dans: [Clemente] Solar DE La MARguerite (éd.), Traités publics de la Royale Maison de Savoie avec les puissances étrangères depuis la paix de Chateau-Cambresis jusqu'à nos jours publiés par ordre du Roi, t. I, Turin 1836, p. 155-176. 
coutume, tout en déplorant les longueurs survenues dans les négociations substantielles ${ }^{231}$. Le mémoire adressé le même jour par Louis XIV à Longueville et à d'Avaux précisa expressément que cette décision était censée favoriser la conclusion de la paix ${ }^{232}$. Sans que l'on en arrivât à un accord formel sur ce point, les Espagnols acceptèrent eux aussi, pour leur part, le principe bilingue, et rédigèrent leur prochain projet de traité et en français et en espagnol ${ }^{233}$.

Au même moment, la crise des relations entre la France et son allié néerlandais devint flagrante par le mauvais accueil fait par les Hollandais à Servien, qui était arrivé à La Haye le 8 janvier 1647 pour négocier avec les alliés la garantie mutuelle du futur traité de paix à conclure à Münster ${ }^{234}$. La péripétie politique entraîna ici encore un incident linguistique dont Mazarin s'inquiéta beaucoup; le 8 février, il écrivit à Servien: „On m'a dict que Messieurs les Estatz avoient respondu en latin à vostre harangue ${ }^{235}$ quoyqu'ilz ne l'ayent jamais faict à aulcun ambassadeur du Roy et qu'ilz ayent tousjours parlé françois. Cela seroit bien mal et j'ay peine à le croire «236. D'une manière analogue, Servien utilise l'expression »parler françois« pour traduire la volonté des Hollandais de se racommoder avec les Français ${ }^{237}$.

La rupture politique peut se traduire d'une manière analogue à la crise, par un durcissement sur le point des langues; par exemple, quand l'électeur de Bavière eut révoqué la trêve passée avec la Suède en mars 1647238 par une lettre en allemand adressée à la reine de Suède, celle-ci perçut cet usage de l'allemand, autrefois admis dans la correspondance avec cet électeur (au moins au niveau des am-

231 Copie: AE, CP All. 99 fol. 152-153'; traduction espagnole dans: Marqués DE LA FUENSANTA del Valle, José Sancho Rayon, Francisco de Zabalburu (éd.), Colección de documentos inéditos para la historia de España, t. 83, Madrid 1885 (réimpression Vaduz 1966), p. 192-195.

232 "Quant à ce qui est de la langue, quoyque le traicté de Vervins n'ayt esté fait qu'en françois, on ne laissera pas de passer sur cet exemple pour faciliter la paix et de consentir qu'on en fasse deux originaux, l'un en françois et l'autre en espagnol, où les deux roys seront nommez à l'accoustumée«, BRAUN, APW II B 5/1, document nº 177, citation p. 832.

233 Negociations secretes, t. IV, p. 224-233.

234 Il n'y a pas encore d'étude particulière sur cette mission en langue française; la plupart des documents qui la concernent sont publiés dans: BRAUN, APW II B 5; ROHRSCHNEIDER, APW II B 6. Pour ce sujet, la meilleure référence reste: J. P. AREND, Algemeene geschiedenis des vaderlands, van de vroegste tijden tot op heden. Achtreenvolgens voortgezet door $O$. Van Rees, W. G. B[r]ill, deerde deel, Van het jaar 1581 tot 1795 na Christus, vijfde stuk, Amsterdam 1868.

235 Discours prononcé par Servien devant l'assemblée des États-Généraux des ProvincesUnies, le 14 janvier 1647, et la réponse des États-Généraux; cf. BraUN, APW II B 5/1, p. 387.

236 Ibid., $n^{\circ} 110$. Cependant, Mazarin avait raison, même si Servien chercha à minimiser l'importance de l'incident, cf. ibid., $\mathrm{n}^{\circ} 150$.

237 Cf. BRAUN, APW II B 5/2, document $n^{\circ} 253$.

238 Traités de trêve conclus à Ulm entre la France, la Suède, la Hesse-Cassel, la Bavière et l'électorat de Cologne; le traité passé par la France a été rédigé en latin, celui passé par la Suède, en allemand, cf. IMMLER, Kurfürst Maximilian I. Pour les publications et les copies qui en existent dans les archives françaises, cf. BraUN, APW II B 5/2, p. 926. 
bassadeurs), comme un affront, et se crut obligée de lui répondre en suédois, en joignant pourtant à l'original de sa lettre, la copie d'une traduction allemande pour en assurer la compréhension ${ }^{239}$. Le caractère très officiel de cette dépêche est souligné par l'ordre royal transmis au maréchal Wrangel de faire accompagner sa remise de sons de trompettes. Il est à noter que la reine elle-même, dans deux lettres adressées respectivement à Wrangel ${ }^{240}$ et à ses plénipotentiaires Oxenstierna et Salvius ${ }^{241}$ du 26 octobre 1647 , justifia son choix linguistique, de sorte que nous disposons par là d'une preuve qui démontre le lien direct qui va de la révocation de la trêve en allemand à la réponse en suédois.

L'emploi d'une certaine langue pouvait par ailleurs déterminer la valeur ou la vocation juridique d'un acte. C'est dans la perspective de leur insertion dans le traité de paix qu'Oxenstierna revendiqua, le 22 février 1647, la rédaction en latin des documents concernant les griefs religieux des états protestants de l'Empire ${ }^{242}$. Les Impériaux lui rappelèrent pourtant qu'ils devaient par la suite servir de base aux jugements des cours de justice dans l'Empire et être insérés dans le recès de la diète, de sorte qu'il fallait les rédiger d'abord en allemand, et puis les traduire de l'allemand en latin ${ }^{243}$.

Pour conclure, il faut s'interroger sur les fondements historiques qui ont déterminé les choix linguistiques du congrès - c'est-à-dire la tradition -, mais s'interroger aussi sur l'impact du congrès même sur sa postérité. Si l'emploi de plusieurs langues était courant lors du congrès de la paix de Westphalie, nos observations montrent que, souvent, leur choix n'était pas facultatif. Il n'est pas complètement faux de voir dans ce congrès une sorte de tour de Babel, mais l'analyse structurelle révèle le rôle politique majeur de l'emploi des langues dans la diplomatie et leurs implications à la fois politiques et juridiques. Cela sert à comprendre pourquoi au congrès de la paix de Westphalie la volonté d'arriver à un accord politique se manifestait souvent par des concessions linguistiques tandis que l'intransigeance dans ce domaine pouvait se révéler le symptôme d'une crise générale ou même de l'échec imminent des négociations.

Le souci constant des négociateurs au congrès de Westphalie de fonder leurs prétentions linguistiques sur la coutume atteste bien l'impact de la tradition sur ce congrès. En revanche, il servit aussi d'exemple à la diplomatie du siècle suivant, marquée par un mélange de latin et de langues vernaculaires (parmi lesquelles le français joua le rôle principal), ainsi que nous l'apprend d'une manière magistrale Frédéric-Charles Moser.

239 Texte suédois: KoHL, APW II C 4, document $n^{\circ} 30$; version allemande: Johann Georg Schleder (éd.), Theatri Evropaei sechster und letzter Theil [...], Francfort/M. 1652, p. 9194. Il en existe aussi une version latine: KoHL, APW II C 4/1, document no 29.

240 Ibid., $n^{\circ} 32$.

241 Ibid., no 31 .

242 Procès-verbal des Impériaux, OschmanN, APW II A 5 , pièce 1 jointe au $\mathbf{n}^{\circ} 277$, ici p. 550 .

${ }_{243}$ Ibid. 


\section{Les problèmes de traduction au congrès de Westphalie}

Les négociations quasi quotidiennes entre puissances souveraines rendirent inéluctable la traduction, problème devenu aigu au congrès de Westphalie. Elle jouait évidemment un rôle éminent dans ce XVII ${ }^{e}$ siècle en marche vers un système international d'États souverains et indépendants, quittant l'universalisme médiéval et brisant les moules uniformisant non seulement la vie religieuse et politique, mais aussi son expression linguistique. Les recherches sur ce sujet servent à approfondir nos connaissances sur les relations internationales, mais également sur l'histoire culturelle de l'Europe. Au congrès et dans les traductions des traités finalement signés en Westphalie, les problèmes terminologiques devenaient particulièrement délicats dans les cas où une langue ne disposait que d'un seul terme pour traduire plusieurs mots d'une autre. C'est ainsi que le mot »évêché« recouvre en français à la fois le champ sémantique des concepts allemands Bistum (c'est-à-dire son district spirituel) et Stift (son district temporel); il était en même temps difficile de traduire des termes fondamentaux du droit public du Saint-Empire pour lesquels le français n'avait pas d'équivalent exact, tels que Landeshoheit, c'est-à-dire la souveraineté limitée des princes et villes de l'Empire, pour laquelle on utilisait parfois, en français, les termes de »supériorité « ou »supériorité territoriale«, pourtant pas unanimement acceptés; souvent on traduisait aussi par »souveraineté« tout court, ce qui pouvait entraîner une confusion avec la >vraie souveraineté, c'est-à-dire la souveraineté absolue des rois et des princes indépendants 244 .

Ces problèmes de traduction feront donc l'objet de nos études sur les versions françaises des concepts latins et allemands du droit constitutionnel du Saint-Empire, que nous avons centrées autour du thème de la souveraineté. Pour l'instant, il suffit de souligner l'influence que la toute première traduction des traités de Westphalie en langue française, publiée dans la »Gazette de France « en novembre et décembre $1648^{245}$, exerça sur quasiment toutes les versions suivantes, jusqu'à sa dernière traduction publiée sous l'Ancien Régime, en 1782 et en 1787, par Simon Jacquet $^{246}$. Les expressions qu'elle avait forgées se retrouvent en fait, dans une très large mesure, dans les traductions postérieures; il y a donc une continuité textuelle qui va de la première version des traités à leur dernière traduction.

Ces dépendances que nous avons pu détecter entre les différentes traductions, d'une part, et les évolutions terminologiques que l'on peut constater, d'autre part, confirment une remarque de Konrad Repgen, qui dit qu'une étude systématique des traductions des actes latins du congrès de la paix de Westphalie en allemand, et inversement des actes allemands en latin, permettrait probablement d'en tirer

244 Cf. BRaUn, Traductions.

245 Cf. ibid.; ID., Die »Gazette de France«; ID., OschmanN, REPGEN, APW III B 1/2.

246 Cf. [Simon] JACQUET, Droit public d'Allemagne [...], 6 vol., Strasbourg 1782, les traités de Westphalie se trouvent au t. V, p. 39-102 (Münster), 103-238 (Osnabrück); [ID.], Recueil precieux et unique des loix fondamentales de l'Empire [...], 2 vol., Strasbourg, Paris 1787, les traités de Westphalie se trouvent au vol. I, avec la même pagination qu'en 1782. 
des conclusions intéressantes sur la conception de la politique et de l'État en $1648^{247}$; il en va de même pour les versions françaises. Le décalage entre les notions de »souveraineté «, ou, pour citer d'autres exemples, de »capitulation impériale«, de »ban d'Empire«, dans la pensée de différents traducteurs et dans celle des auteurs qui ont utilisé leurs traductions, peut en effet être considérable et ces notions mêmes attachées à des théories d'État divergentes. De sorte que si l'histoire des idées politiques veut intégrer l'image et la connaissance de la culture juridique d'un pays à l'étranger (concrètement la compréhension du droit public de l'Allemagne en France), elle doit nécessairement passer par ces traductions. Les différentes idées qu'on peut avoir en France sur la nature du gouvernement du Saint-Empire et qui vont de la monarchie sous un empereur absolu à la remise en cause de son caractère même d'État, en passant par le modèle du status mixtus, s'intègrent en effet toutes dans des courants intellectuels plus ou moins répandus à l'époque et qui n'évoluent pas de façon ésotérique, mais en fonction d'un échange et d'une critique mutuelle constants, et s'inspirant notamment des changements dans l'Empire et des progrès de sa jurisprudence. Ces échanges mutuels d'idées attestent bien l'existence, dans le monde de l'esprit, d'une civilisation européenne qui se place au-dessus des nationalités, et dont l'histoire serait incomplète sans celle de leur support principal qu'est la traduction. C'est pour cela que L. G. Kelly a pu dire: »L'Europe occidentale doit sa civilisation aux traducteurs $\aleph^{248}$. Ce que nous voudrions nommer »une civilisation européenne - expression peut-être un peu audacieuse mais qui ne cherche aucunement à nier les différences qui existent, par exemple, entre la France et le Saint-Empire - semble pourtant bien avoir existé, et Françoise Waquet l'appelle »une Europe intellectuelle unitaire ${ }^{249}$.

\section{La traduction et l'opinion publique au temps du congrès de Westphalie}

Or, les problèmes de la traduction au congrès de Westphalie ne concernent pas uniquement les grands thèmes du droit d'État et la communication entre les envoyés au congrès proprement dit, ou la terminologie litigieuse de certaines stipulations. Ils concernent en même temps la communication du congrès avec le monde extérieur, son image dans l'opinion publique; la publication de la traduc-

247 REPGEN, Westfälische Friede und Öffentlichkeit, p. 750.

248 Kelly, The True Interpreter, p. 1. Voir aussi Gérald CHAIX, Aux sources d'une civilisation européenne, dans: Le Monde des livres (18 décembre 1998), p. X.

249 WAQUET, Le latin, p. 9. Certes, cette Europe se limite, du point de vue linguistique, aux seules élites, princières ou bourgeoises. Cf. aussi, à ce sujet, MEYER, L'éducation des princes, p. 129: „Il existe une véritable Europe linguistique multilingue fondée sur un tri-, ou quadri-, linguisme à base fondamentale de latin-français. L'exemple princier se répercute dans une partie de la profondeur sociale, englobant dans l'Europe des princes celles des élites nobiliaires et princières, en opposition avec le maintien des langues vernaculaires populaires«. Pour le rôle du latin dans l'éducation princière, voir aussi FLANDROIS, L'institution, p. 137-139. 
tion d'un document, qu'on retrouve fréquemment dans les journaux au milieu du XVIIe siècle tout comme dans notre presse contemporaine, est en effet en même temps un moyen d'information et un élément de propagande auquel les autorités recourent volontiers pour justifier leurs choix politiques, et qu'elles favorisent par conséquent ${ }^{250}$. Par ailleurs, comme l'a montré une grande étude de Konrad Repgen sur la paix de Westphalie et l'opinion publique (allemande) ${ }^{251}$, elle correspond aussi à un besoin réel d'information de la part du public, et lui fournit des renseignements assez fiables.

Dans cette optique, on peut noter que la publication des traductions n'exerce pas seulement une influence considérable sur l'image du congrès à l'extérieur, mais que les réactions qu'elle suscite ont aussi un effet sur la politique future du congrès même. En fait, quand les plénipotentiaires français eurent envoyé, au printemps 1644, leur première lettre circulaire aux états de l'Empire afin de les inviter au congrès, Théophraste Renaudot fit lui-même la traduction de cette pièce en français et la publia dans sa »Gazette de France «252. Or, comme il s'était permis de durcir encore un peu le ton, en qualifiant par exemple l'empereur de »tyran«, sa traduction suscita parmi les Impériaux un vif émoi que les Français avaient tout intérêt à éviter, parce qu'une forte réaction de la part de l'empereur eût peut-être pu dissuader les princes et les villes d'envoyer leurs députés au congrès, ce qui était contraire aux objectifs de la France. Le 10 juin 1644, les médiateurs vinrent voir les plénipotentiaires français pour leur faire part des plaintes des Impériaux au sujet de cette traduction, qui »ne semble pas bienscéant à des Ambassadeurs qui disent estre venuz pour traicter la paix et restablir l'amitié « 253 . $\mathrm{Si}$, le 2 juillet 1644, Mazarin écrivait encore que la »reyne fait faire recherche pour en faire exemple de l'autheur de la traduction de vostre lettre circulaire, et elle ne veut pas que les termes injurieux qu'on y a supposéz contre la personne de l'Empereur demeurent sans chastiment «, Brienne disposait déjà, le même jour, d'informations plus précises et estima que l'empereur n'aurait pas lieu de se plaindre de la lettre écrite par les plénipotentiaires, mais seulement »des motz offensans ajoustéz en la traduction qui a esté faicte et imprimée par le gassetier [Renaudot] «254. Et d'annoncer que les ambassadeurs auraient »au premier jour l'arrest portant déffence de débiter cette belle traduction [comme s'exprimait Brienne] qui sera remply de parolles aigres contre l'auteur «255. D'Avaux se crut pourtant obligé de justifier cette lettre qu'il avait minutée, en soulignant que ses termes étaient »assés

${ }^{250}$ Les délégations présentes en Westphalie acquéraient même fréquemment ces sortes d'imprimés pour en tirer des informations, cf. BosBACH, Gedruckte Informationen.

251 Cf. REPGEN, Westfälische Friede und Öffentlichkeit.

252 Gazette [de France] no 55, daté du 25 mai 1644, p. 353-360.

253 Cf. la lettre adressée par Servien à Brienne le lendemain, IRSIGLER, APW II B 1, document $n^{\circ} 138$. Brienne répondit le 25 juin: »Je [...] n'ay pas veu la traduction [...], mais j'ay ordre de faire faire recherche des exemplaires et du traducteur, et ne l'ayant rendu fidèllement il sera chastié «, ibid., no 148 , citation p. 286.

254 Ibid., documents nos 153 et 154 , citations p. 301 et 304 .

255 Ibid. 
mesurés« et que les mots de »tyrannie«, d'»usurpation«, etc. relevés dans la traduction n'y étaient pas employés 256 .

Néanmoins, comme Brienne dut le constater la semaine suivante ${ }^{257}$, les plaintes avancées contre la traduction de Renaudot continuaient. La dureté de la traduction venait en effet très mal à propos alors que la diplomatie française, pour arriver à ses fins, avait tout intérêt à éviter un grand émoi parmi les états de l'Empire; or, comme d'Avaux et Servien l'écrivirent à la reine le 16 juillet, l'empereur s'était offensé de la convocation des princes et des villes au congrès et »n'a pas honte de faire dire de sa part dans la diètte de Francfort que nous sommes descheuz de la seureté de noz passeportz par cette procédure qu'il appelle séditieuse, affin d'exciter quelqu'un à entreprendre contre noz personnes impunément «258.

Le gouvernement français était bien conscient de l'impact que les pamphlets et les brochures pouvaient avoir sur la politique du congrès. Quand Abel Servien négociait à La Haye le traité de garantie mutuelle, passé entre la France et les Provinces-Unies le 29 juillet 1647, il envoyait régulièrement à Mazarin les pamphlets qui étaient publiés aux Pays-Bas ${ }^{259}$. Mazarin savait d'ailleurs que tous les documents politiques étaient susceptibles d'être imprimés et traduits dans ce pays. Il était en même temps conscient de la nécessité d'influencer l'opinion publique néerlandaise à travers des traductions. Cela résulte clairement de la réponse qu'il fit à Servien au sujet de sa lettre circulaire adressée aux différentes provinces qui faisaient partie des États-Généraux, à l'exception de la Hollande, le 26 avril 1647260 . En effet, Mazarin écrivit à Servien, le 10 mai: "Je ne doute point que vostre lettre conceue aux termes qu'elle est, n'ayt faict grand effect en tous les espritz, et si je ne croyois qu' aussitost qu'une pièce comme celle-là paroist, on en faict de tous costés des traductions en la langue du pays, je vous recomanderois de

256 Lettre à Servien, 6 juillet 1644 , ibid., no 158 , ici p. 321. C'est pour cela que Brienne put constater avec satisfaction le 9 juillet: $»[$ L'ambassadeur vénitien Nani] m'a porté de la part dudict Contarini la plaincte que font les ministres impériaux de la liberté avec laquelle on imprime de deçà, et luy ayant dit que l'on avoit résolu un arrest pour en réprimer la licence, il m'a tesmoigné en demeurer satisfait. Et moy, je l'ay esté entièrement apprenant que la collère des Impériaux se restrainct sur celuy qui a failly et non contre vous «, ibid., $\mathrm{n}^{\circ} 161$, citation p. 335.

257 Ibid., $\mathrm{n}^{\circ} 171$.

258 Ibid., no 173, citation p. 357. Le 23 juillet, Brienne annonça que Renaudot avait été puni pour sa fâcheuse amplification de la circulaire, sans toutefois entrer dans les détails, ibid., $\mathrm{n}^{\circ} 179$, ici p. 383. Les ambassadeurs français applaudirent cette "correction « et soulignèrent la nécessité de réprimer les »extravagances« et les »diffamations « de la presse (ibid., $\mathrm{n}^{\circ} 182$, ici p. 397-398); pourtant, le 15 octobre, ils eurent de nouveau à se plaindre d'un article de Renaudot, qui contrariait leur politique au congrès (lettre à Brienne, ibid., no 270, ici p. 558). Pour l'affaire de la circulaire, Brienne autorisa le 6 août d'Avaux et Servien à faire imprimer en Hollande une pièce pour répliquer à la critique de l'empereur; ce manifeste, précisa-t-il, devait être dressé »en langue latine, affin qu'il ayt plus de cours dans l'Allemagne«, ibid., $\mathrm{n}^{\circ} 192$, ici p. 426.

259 Cf., par exemple, la pièce jointe à la lettre adressée par Servien à Mazarin, La Haye, 5 mars 1647: BrAUN, APW II B 5/1, pièce 1 jointe au no 161, p. 765.

260 Cf. ibid., t. $5 / 2$, pièce 1 jointe au $n^{\circ} 250$, p. 1191-1192. 
prendre une autre fois le soing d'y faire travailler à mesure que vous la composez «261. En effet, la lettre circulaire a été publiée à plusieurs reprises, aux XVIIe et XVIII ${ }^{\mathrm{e}}$ siècles, en français, en hollandais, en latin et en italien ${ }^{262}$.

\section{Le congrès de Westphalie et la tradition des langues diplomatiques}

En guise de conclusion de nos observations sur les coutumes linguistiques attestées dans la diplomatie au milieu du XVIIe siècle, on peut noter qu'outre la langue diplomatique la plus importante, le latin - qui n'était plus la seule langue véhiculaire des diplomates ${ }^{263}$, mais était restée la principale langue de rédaction des traités ${ }^{264}$ et la lingua communis du monde occidental latin - l'italien et le français, notamment, s'étaient imposés comme langues des négociations orales et écrites ainsi que, dans une moindre mesure, l'allemand, le néerlandais et l'espagnol; outre le latin (traités de paix de Münster et d'Osnabrück du 24 octobre 1648), on eut recours au français et au néerlandais pour la rédaction des traités (paix entre l'Espagne et les Pays-Bas du 30 janvier 1648 rédigée en deux langues, suite à un accord du 5 mai 1646).

La diversité des langues dont se servaient les négociateurs et leur usage (apparemment) indifférent dans de nombreux cas font penser à une confusion de langues comparable à celle qui suivit la construction de la tour de Babel. Cependant, une analyse structurelle relativise cette impression et révèle qu'en matière diplomatique le recours à une langue joue un rôle politique éminent et a des implications de droit public; le recours à leur propre langue (l'allemand ou le latin pour le Saint-Empire) par les diplomates était en effet une caractéristique de la souveraineté étatique ${ }^{265}$. Moins âprement discutés que les questions du cérémonial concernant la préséance, ces problèmes linguistiques n'étaient par consé-

261 Ibid., no 269 , ici p. 1275.

${ }^{262}$ Les premières éditions de la lettre datent très certainement de 1647; par ailleurs, un imprimé de cette pièce se trouve parmi la correspondance diplomatique concernant la mission de Servien en Hollande, conservée au Quai d'Orsay, cf. ibid., p. 1191.

263 La fut-il jamais absolument?

264 Cf. aussi M[onique] ConSTANT, article "Traités«, dans: BÉLY (dir.), Dictionnaire de l'Ancien Régime, p. 1222.

${ }^{265}$ Ce même principe régira encore les relations diplomatiques au XIX ${ }^{\mathrm{e}}$ siècle: »Le principe qui domine tout, c'est que le droit d'égalité des États s'étend aussi sur la langue qu'emploient leurs gouvernements dans leurs relations diplomatiques. Chaque État souverain est, par conséquent, en droit de se servir exclusivement, et de demander qu'on se serve avec lui d'une langue quelconque par lui déterminée, soit de celle de son pays, soit d'une langue étrangère, et les autres États ont également le droit de ne point obtempérer à ce désir«, PRADIER-FODÉRÉ, Cours de droit diplomatique, t. II, p. 459-460, n. 1 (texte initialement publié dans le "Courrier diplomatique « du 31 janvier 1872). Et d'ajouter: „C'est pour cela que le latin, - langue morte, - était admirablement propre, par sa neutralité, à jouer le rôle d'idiome commun, sans compter sa précision qui en fait la langue scientifique par excellence $\ll$, ibid. 
quent pas négligés par les délégations et les gouvernements au temps du congrès de Münster et d'Osnabrück, en particulier par les Français.

Pour élaborer et perfectionner la terminologie de droit international et de droit public, le congrès eut recours aux précédents offerts par les négociations et les traités (bilatéraux) antérieurs. Il servit cependant lui-même d'exemple, du moins pour le siècle qui suivit la paix de Westphalie. Pendant cette époque, le français réussit à s'imposer comme langue diplomatique de même importance que le latin; deux pays imposèrent au reste de l'Europe leurs langues officielles: la France, dont le rayonnement culturel faisait du français la première langue européenne, et le Saint-Empire, insistant sur l'usage du latin, sa deuxième langue officielle, à côté de l'allemand, depuis l'avènement de Charles Quint. Face à l'essor du français, l'Empire lui-même, et ce par l'intermédiaire de l'empereur ou de quelquesunes des principautés, prit ainsi la défense de sa romanité et du latin dans le cadre des relations diplomatiques. Certes, le latin n'était pas seulement la langue de l'Empire, qui se nommait »romain«, mais la langue commune à tous les pays de l'Occident ${ }^{266}$.

Sur le plan de la traduction, les solutions apportées pendant le congrès aux problèmes posés par l'emploi de plusieurs langues diplomatiques ont servi de référence aux traducteurs du siècle suivant. C'est ainsi que, pour les traductions en français - seconde grande langue diplomatique des XVIIe et XVIIIe siècles - des termes de droit public et de droit international latins figurant dans les traités de paix du 24 octobre 1648, on peut constater que les premières qui ont été réalisées (et publiées) pendant le congrès, ou peu après son achèvement, ont durablement influencé et marqué la manière dont la paix de Westphalie a été reçue en France au cours du siècle qui a suivi sa signature. Dans ce contexte, la traduction se révèle être la source, jusqu'ici largement négligée par les historiens, des idées de droit public dans l'Europe de la paix de Westphalie et l'élément indispensable et fondamental d'une histoire intellectuelle des idées politiques en Europe.

La continuité dans les solutions apportées aux problèmes de traduction se retrouve d'une manière analogue dans le domaine de l'emploi des langues proprement dit. Le souci constant des négociateurs au congrès de Westphalie de fonder leurs prétentions linguistiques sur la coutume atteste bien l'impact de la tradition sur celui-ci. En revanche, son influence sur sa postérité s'explique en partie par le fait qu'il devint le modèle des congrès futurs et que ses actes étaient dans une large mesure publiés et donc accessibles; nous voyons par exemple Moser recourir fréquemment au journal (déjà publié, en 1710, par Cortrejus) du plénipotentiaire impérial au congrès, Volmar. Le choix que fait Moser en commençant pour

266 Il ne faut donc pas succomber à la tentation d'adopter d'une manière trop insouciante la perspective império-centriste de Moser: ce n'est évidemment pas seulement l'Empire qui prend la défense du latin, mais aussi, d'une manière plus générale, les puissances de l'Europe centrale et du Nord (sans oublier Rome, bien sûr), dont notamment la Suède et la Pologne; pour cette dernière, cf. M. SERWANSKI, La diplomatie polonaise au XVIIe siècle, dans: BÉLY (dir.), L'invention de la diplomatie, p. 167-176, ici p. 173-174. 
l'essentiel son traité au moment du congrès de la paix de Westphalie ne semble par conséquent pas fortuit.

Toutefois, nous ne voudrions pas nier que le congrès de Westphalie fut le dernier apogée du latin dans la diplomatie européenne. C'est la conclusion qu'avance Dickmann et à laquelle nous n'hésitons pas à souscrire. Cependant, le latin, même perdant incontestablement de son importance, restera bien vivant dans la diplomatie du siècle suivant. De ce fait, le congrès de Münster et d'Osnabrück ne marque point un changement brutal, il n'est pas le "portique qui mène d'un monde à un autre ${ }^{267}$, mais sert dans une certaine mesure à perpétuer la tradition antérieure en fournissant un exemple aux générations futures de diplomates, ce qui nous permet de qualifier le siècle suivant, en matière d'emploi des langues, de l'époque de la diplomatie de Westphalie ${ }^{268}$, sans que nous attachions à cette notion, très à la mode ${ }^{269}$, une valeur autre que linguistique. L'analyse des aspects linguistiques du congrès de la paix de Westphalie nous révèle un monde en transition, mais non en perte de tradition. Servien ${ }^{270}$ soulignait lui aussi la valeur de la tradition dans le domaine du cérémonial et croyait que: »il valloit mieux prendre des expédiens qui laissassant un chacun dans la pocession du droict que chacun prétend luy appartenir que de s'esloigner des anciennes coustumes ny rien céder positivement dans une occasion sy célèbre « et qui (pourrions-nous ajouter aujourd'hui) devait effectivement servir, à son tour, de règle de conduite à la postérité.

267 Voir la citation ci-dessus.

$268 \mathrm{Si}$ le congrès de Westphalie devint la référence du siècle suivant, son caractère polygiotte et le >combat < entre le latin et les langues vernaculaires n'étaient pas particuliers à cette époque, comme on peut le voir à propos de Charles Quint (ajoutons un autre exemple: quand ce dernier rédigea une déclaration contre Luther en langue française, le 19 avril 1521 , sa publication fut prévue non seulement en français, mais aussi en latin, en italien, en allemand, en espagnol et en néerlandais); la particularité de cette période est plutôt le recours fréquent au congrès de Westphalie comme point de repère. La déclaration de Charles Quint se trouve dans: Adolf WREDE (éd.), Deutsche Reichstagsakten unter Kaiser Karl V., vol. 2, Gotha 1896 (Deutsche Reichtagsakten, Jüngere Reihe, 2).

269 Pour la critique du concept, cf. notamment DuchHARDT, Westphalian System.

270 Dans sa lettre à Brienne du 9 avril 1644 , dont nous avons parlé ci-dessus et dont nous pouvons ainsi reprendre la citation. 
